Cochrane Database of Systematic Reviews

\title{
Ab interno trabecular bypass surgery with Schlemm 's canal microstent (Hydrus) for open angle glaucoma (Review)
}

Otarola F, Virgili G, Shah A, Hu K, Bunce C, Gazzard G

Otarola F, Virgili G, Shah A, Hu K, Bunce C, Gazzard G.

Ab interno trabecular bypass surgery with Schlemm's canal microstent (Hydrus) for open angle glaucoma.

Cochrane Database of Systematic Reviews 2020, Issue 3. Art. No.: CD012740.

DOI: 10.1002/14651858.CD012740.pub2.

www.cochranelibrary.com 
TABLE OF CONTENTS

HEADER

ABSTRACT

PLAIN LANGUAGE SUMMARY

SUMMARY OF FINDINGS

BACKGROUND

OBJECTIVES

METHODS

RESULTS

Figure 1.

Figure 2.

Figure 3.

Figure 4.

Figure 5.

Figure 6.

DISCUSSION

AUTHORS' CONCLUSIONS

ACKNOWLEDGEMENTS

REFERENCES

CHARACTERISTICS OF STUDIES

DATA AND ANALYSES

Analysis 1.1. Comparison 1 Cataract surgery + Hydrus microstent vs cataract surgery (CS) alone, Outcome 1 Proportion dropfree: short-term (6 to 18 months).

Analysis 1.2. Comparison 1 Cataract surgery + Hydrus microstent vs cataract surgery (CS) alone, Outcome 2 Proportion dropfree: medium-term (18 to 36 months).

Analysis 1.3. Comparison 1 Cataract surgery + Hydrus microstent vs cataract surgery (CS) alone, Outcome 3 Mean change in IOP measured using Goldmann applanation tonometry: medium-term (18 to 36 months).

Analysis 1.4. Comparison 1 Cataract surgery + Hydrus microstent vs cataract surgery (CS) alone, Outcome 4 Mean change in IOP-lowering drops instilled per day: medium-term (18 to 36 months).

Analysis 1.5. Comparison 1 Cataract surgery + Hydrus microstent vs cataract surgery (CS) alone, Outcome 5 Proportion of participants requiring additional glaucoma surgery or laser.

Analysis 1.6. Comparison 1 Cataract surgery + Hydrus microstent vs cataract surgery (CS) alone, Outcome 6 Adverse events: loss of $2+V A$ lines.

Analysis 1.7. Comparison 1 Cataract surgery + Hydrus microstent vs cataract surgery (CS) alone, Outcome 7 Adverse events: IOP spike $>10 \mathrm{mmHg}$.

Analysis 1.8. Comparison 1 Cataract surgery + Hydrus microstent vs cataract surgery (CS) alone, Outcome 8 Adverse events: bleeding.

Analysis 2.1. Comparison 2 Hydrus microstent vs iStent trabecular micro-bypass stent, Outcome 1 Proportion drop-free: shortterm (6 to 18 months).

Analysis 2.2. Comparison 2 Hydrus microstent vs iStent trabecular micro-bypass stent, Outcome 2 Mean change in IOP measured using Goldmann applanation tonometry: short-term (6 to 18 months).

Analysis 2.3. Comparison 2 Hydrus microstent vs iStent trabecular micro-bypass stent, Outcome 3 Mean change in IOP-lowering drops instilled per day: short-term (6 to 18 months).

Analysis 2.4. Comparison 2 Hydrus microstent vs iStent trabecular micro-bypass stent, Outcome 4 Proportion of participants with IOP $<21 \mathrm{mmHg}$.

APPENDICES

CONTRIBUTIONS OF AUTHORS

DECLARATIONS OF INTEREST

SOURCES OF SUPPORT

DIFFERENCES BETWEEN PROTOCOL AND REVIEW

1

1

2

4

9

Ab interno trabecular bypass surgery with Schlemm 's canal microstent (Hydrus) for open angle glaucoma (Review) 
[Intervention Review]

\section{Ab interno trabecular bypass surgery with Schlemm 's canal microstent (Hydrus) for open angle glaucoma}

Francisco Otarola1,2a, Gianni Virgili3b, Anupa Shah4, Kuang Hu¹, Catey Bunce ${ }^{5}$, Gus Gazzard ${ }^{1,6}$

1Glaucoma Service, Moorfields Eye Hospital NHS Foundation Trust, London, UK. 2Centro de la Visión, Clínica las Condes, Santiago, Chile. ${ }^{3}$ Department of Neurosciences, Psychology, Drug Research and Child Health (NEUROFARBA), University of Florence, Florence, Italy. ${ }^{4}$ Cochrane Eyes and Vision, ICEH, London School of Hygiene \& Tropical Medicine, London, UK. ${ }^{5}$ School of Population Health \& Environmental Sciences, Faculty of Life Sciences \& Medicine, King's College London, London, UK. 6Institute of Ophthalmology UCL \& NIHR Biomedical Research Centre, London, UK

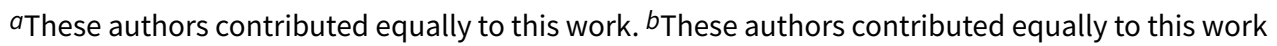

Contact address: Francisco Otarola, Glaucoma Service, Moorfields Eye Hospital NHS Foundation Trust, 162 City Road, London, EC1V 2PD, UK. fjotarola@gmail.com.

Editorial group: Cochrane Eyes and Vision Group

Publication status and date: New, published in Issue 3, 2020.

Citation: Otarola F, Virgili G, Shah A, Hu K, Bunce C, Gazzard G. Ab interno trabecular bypass surgery with Schlemm 's canal microstent (Hydrus) for open angle glaucoma. Cochrane Database of Systematic Reviews 2020, Issue 3. Art. No.: CD012740. DOI: 10.1002/14651858.CD012740.pub2.

Copyright @ 2020 The Cochrane Collaboration. Published by John Wiley \& Sons, Ltd.

\section{A B S T R A C T}

\section{Background}

Glaucoma is a leading cause of irreversible blindness. A number of minimally-invasive surgical techniques have been introduced as a treatment to prevent glaucoma from progressing; ab interno trabecular bypass surgery with the Schlemm's canal Hydrus microstent is one of them.

\section{Objectives}

To evaluate the efficacy and safety of ab interno trabecular bypass surgery with the Hydrus microstent in treating people with open angle glaucoma (OAG).

\section{Search methods}

On 7 May 2019, we searched CENTRAL (2019, Issue 5), which contains the Cochrane Eyes and Vision Trials Register; Ovid MEDLINE; Ovid Embase; the ISRCTN registry; ClinicalTrials.gov; and the WHO ICTRP.

\section{Selection criteria}

We searched for randomised controlled trials (RCTs) of the Hydrus microstent, alone or with cataract surgery, compared to other surgical treatments (cataract surgery alone, other minimally-invasive glaucoma device techniques, trabeculectomy), laser treatment, or medical treatment.

\section{Data collection and analysis}

A minimum of three authors independently extracted data from reports of included studies, using a data collection form and analysed data, based on standard Cochrane methods.

\section{Main results}

We included three published studies, with 808 people randomised. Two studies had multiple international recruitment centres in the USA and other countries. The third study had several sites based in Europe. All three studies were sponsored by the Hydrus manufacturer Ivantis 
Inc. All studies included participants with mainly mild or moderate OAG (mean deviation between -3.6 dB (decibel) and -8.4 dB in all study arms), which was controlled with medication in many participants (mean medicated intraocular pressure (IOP) $17.9 \mathrm{mmHg}$ to $19.1 \mathrm{mmHg}$ ). There were no concerns regarding allocation concealment bias, but masking of outcome assessors was high or unclear risk in all studies; masking of participants was achieved, and losses to follow-up were not a concern.

Two studies compared the Hydrus microstent combined with cataract surgery to cataract surgery alone, in participants with visually significant cataracts and OAG.

We found moderate-certainty evidence that adding the Hydrus microstent to cataract surgery increased the proportion of participants who were medication-free from about half to more than three quarters at 12-month, short-term follow-up (risk ratio (RR) 1.59, 95\% confidence interval (CI) 1.39 to 1.83; 2 studies, 639 participants; $I^{2}=0 \%$; and 24-month, medium-term follow-up (RR 1.63, $95 \%$ Cl 1.40 to $1.88 ; 2$ studies, 619 participants; $\left.I^{2}=0 \%\right)$.

The Hydrus microstent combined with cataract surgery reduced the medium-term mean change in unmedicated IOP (after washout) by $2 \mathrm{mmHg}$ more compared to cataract surgery alone (mean difference (MD) $-2.00,95 \% \mathrm{Cl}-2.69$ to $-1.31 ; 2$ studies, 619 participants; $\mathrm{I}^{2}=0 \%$; moderate-certainty evidence), and the mean change in IOP-lowering drops (MD $-0.41,95 \% \mathrm{Cl}-0.56$ to $-0.27 ; 2$ studies, 619 participants; $\mathrm{I}^{2}=0 \%$; low-certainty evidence). We also found low-certainty evidence that adding a Hydrus microstent to cataract surgery reduced the need for secondary glaucoma surgery from about $2.5 \%$ to less than $1 \%$ (RR $0.17,95 \% \mathrm{Cl} 0.03$ to $0.86 ; 2$ studies, 653 participants; $I^{2}=27 \%$; low-certainty evidence).

Intraocular bleeding, loss of 2 or more visual acuity (VA) lines, and IOP spikes of $10 \mathrm{mmHg}$ or more were rare in both groups; estimates were imprecise, and included both beneficial and harmful effects. There were no cases of endophthalmitis in either group.

No data were available on the proportion of participants achieving IOP less than $21 \mathrm{mmHg}, 17 \mathrm{mmHg}$, or $14 \mathrm{mmHg}$; health-related quality of life (HRQOL), or visual field progression.

One study provided short-term data for the Hydrus microstent compared with the iStent trabecular micro-bypass stent (iStent: implantation of two devices in a single procedure) in 152 participants with OAG (148 in analyses). Use of the Hydrus increased the proportion of medication-free participants from about a quarter to about half compared to those who received iStent, but this estimate was imprecise (RR 1.94, 95\% CI 1.21 to 3.11; low-certainty evidence). Use of the Hydrus microstent reduced unmedicated IOP (after washout) by about $3 \mathrm{mmHg}$ more than the iStent (MD -3.10, 95\% Cl -4.17 to -2.03; moderate-certainty evidence), and the use of IOP-lowering medication (MD $-0.60,95 \% \mathrm{Cl}-0.99$ to -0.21 ; low-certainty evidence). Both devices achieved a final IOP $<21 \mathrm{mmHg}$ in most participants (Hydrus microstent: $91.8 \%$; iStent: $84 \%$; RR 1.09, $95 \% \mathrm{Cl} 0.97$ to 1.23 ; low-certainty evidence).

None of the participants who received the Hydrus microstent $(\mathrm{N}=74)$ required additional glaucoma surgery; two participants who received the iStent $(\mathrm{N}=76)$ did.

Few adverse events were found in either group.

No data were available on the proportion of participants achieving IOP less than $17 \mathrm{mmHg}$ or $14 \mathrm{mmHg}$, or on HRQOL.

\section{Authors' conclusions}

In people with cataracts and generally mild to moderate OAG, there is moderate-certainty evidence that the Hydrus microstent with cataract surgery compared to cataract surgery alone, likely increases the proportion of participants who do not require IOP lowering medication, and may further reduce IOP at short- and medium-term follow-up.

There is moderate-certainty evidence that the Hydrus microstent is probably more effective than the iStent in lowering IOP of people with OAG in the short-term.

Few studies were available on the effects of the Hydrus microstent, therefore the results of this review may not be applicable to all people with OAG, particularly in selected people with medically uncontrolled glaucoma, since IOP was controlled with medication in many participants in the included studies. Complications may be rare using the Hydrus microstent, as well as the comparator iStent, but larger studies are needed to investigate its safety.

\section{PLAIN LANGUAGE SUMMARY}

\section{Ab interno trabecular bypass surgery with Schlemm's canal Hydrus microstent for open angle glaucoma}

\section{What was the aim of the review?}

The aim of this Cochrane Review was to find out if ab interno trabecular bypass surgery with the Hydrus microstent lowers the pressure in the eye (intraocular pressure) for people with open angle glaucoma (OAG). The Cochrane Review authors collected and analysed all relevant studies to answer this question, and found three completed studies.

\section{Key messages}


In people with cataracts and glaucoma, having combined treatment of cataract surgery and a Hydrus implant may increase the number of people who do not need intraocular pressure (IOP) lowering medication (drugs), and may further reduce IOP compared with cataract surgery alone in the short- and medium-term. Where the Hydrus microstent was compared to iStent, the microstent was probably more effective in people with OAG. This evidence was from studies on people in whom IOP was often well-controlled with medication, and their OAG was mainly mild or moderate.

\section{What was studied in the review?}

Glaucoma is a common eye condition and can cause blindness if left untreated. In glaucoma, the optic nerve (which connects the eye to the brain) is damaged, often due to increased pressure in the eye as a result of build-up of fluid. Ab interno trabecular bypass surgery with a Hydrus microstent is a type of surgery in which doctors implant the Hydrus (a small device that opens up a channel in the main fluid canal called Schlemm's) and improves the flow of fluid through this canal. This may lead to lower eye pressure and a lower chance of damage to the optic nerve. This type of surgery is less invasive, and may lead to fewer complications and faster healing times than other types of surgery for glaucoma.

\section{What were the main results of the review?}

Two studies (653 participants with cataracts and open angle glaucoma) found that the proportion of people not using IOP lowering medication at two years was about half for those who received cataract surgery alone, and was more than three-quarters if the Hydrus microstent was also implanted during cataract surgery; this evidence was of moderate-certainty because of problems with study quality. About one in 30 or 50 participants needed further glaucoma surgery after cataract surgery alone, compared with one in 100 or less when the Hydrus microstent was added; this evidence was of low-certainty, because of problems with study quality and the small number of glaucoma surgeries.

Another study (152 participants with open angle glaucoma) compared a Hydrus implant with an iStent implant (a small tube implanted into the eye's drainage system, known as the trabecular meshwork, allowing fluid to flow in the Schlemm's canal) at one year. The study found that the Hydrus microstent nearly doubled the number of people not using IOP lowering medication at one year, from about a quarter to almost a half; this evidence was of low-certainty, because of problems with study quality and the small number of participants. Further glaucoma surgery was very rarely needed in either group.

All included studies were sponsored by the Hydrus manufacturer Ivantis Inc.

The use of the Hydrus implant was probably safe in these studies, but larger studies and a longer follow-up may be needed to investigate very rare or long-term adverse events. This evidence was from studies on people in whom IOP was often well-controlled with medication, and further trials are needed for participants with uncontrolled glaucoma.

\section{How up-to-date is the review?}

The Cochrane Review authors searched for studies published up to 7 May 2019. 


\begin{tabular}{|c|c|c|c|c|c|c|}
\hline \multicolumn{7}{|c|}{ 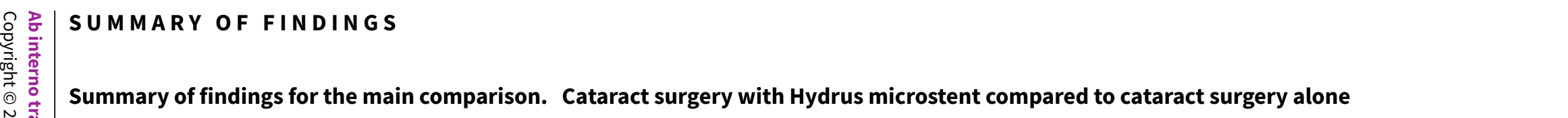 } \\
\hline \multicolumn{7}{|c|}{ Cataract surgery with Hydrus microstent compared to cataract surgery alone } \\
\hline \multicolumn{7}{|c|}{$\begin{array}{l}\text { Patient or population: people with cataracts and open angle glaucoma, many of whom had mild or moderate glaucoma, which was well-controlled with medication } \\
\text { Setting: eye clinics with surgical facilities } \\
\text { Intervention: Hydrus microstent (Hydrus) plus cataract surgery } \\
\text { Comparison: cataract surgery alone }\end{array}$} \\
\hline \multirow[t]{2}{*}{ Outcomes } & \multicolumn{2}{|l|}{ Anticipated absolute effects ${ }^{\star}(95 \% \mathrm{Cl})$} & \multirow{2}{*}{$\begin{array}{l}\text { Relative ef- } \\
\text { fect } \\
(95 \% \mathrm{CI})\end{array}$} & \multirow{2}{*}{$\begin{array}{l}\text { No of partici- } \\
\text { pants } \\
\text { (studies) }\end{array}$} & \multirow{2}{*}{$\begin{array}{l}\text { Certainty of } \\
\text { the evidence } \\
\text { (GRADE) }\end{array}$} & \multirow[t]{2}{*}{ Comments } \\
\hline & Risk with cataract surgery alone & Risk with cataract surgery with Hydrus & & & & \\
\hline $\begin{array}{l}\text { Proportion } \\
\text { of partici- } \\
\text { pants who } \\
\text { were med- } \\
\text { ication-free } \\
\text { (not using } \\
\text { eye drops) }\end{array}$ & Study population & & \multirow{2}{*}{$\begin{array}{l}\text { RR } 1.63 \\
\text { (1.40 to } 1.88)\end{array}$} & \multirow{2}{*}{$\begin{array}{l}619 \\
(2 \mathrm{RCTs})\end{array}$} & \multirow{2}{*}{$\begin{array}{l}\oplus \oplus \oplus \ominus \\
\text { Moderate }^{a}\end{array}$} & \\
\hline $\begin{array}{l}\text { pants who } \\
\text { were med- } \\
\text { ication-free } \\
\text { (not using } \\
\text { eye drops) } \\
\text { medi- } \\
\text { um-term fol- } \\
\text { low-up at } 24 \\
\text { months }\end{array}$ & 480 per 1000 & $\begin{array}{l}782 \text { per } 1000 \\
\text { (671 to } 902)\end{array}$ & & & & \\
\hline 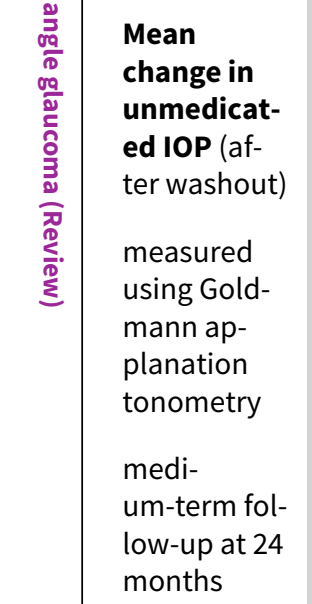 & $\begin{array}{l}\text { The mean change in unmedicated IOP } \\
\text { in the cataract surgery group was }-5.95 \\
\mathrm{mmHg}\end{array}$ & $\begin{array}{l}\text { The MD in the cataract surgery plus Hy- } \\
\text { drus group was } 2 \mathrm{mmHg} \text { lower } \\
\text { (2.69 lower to } 1.31 \text { lower) }\end{array}$ & - & $\begin{array}{l}619 \\
\text { (2 RCTs) }\end{array}$ & $\begin{array}{l}\oplus \oplus \oplus \ominus \\
\text { Moderate }^{a}\end{array}$ & \\
\hline
\end{tabular}

itht or population: people with cataracts and open angle glaucoma, many of whom had mild or moderate glaucoma, which was well-controlled with medication 


\begin{tabular}{|c|c|c|c|c|c|c|}
\hline 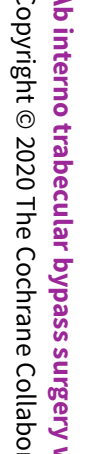 & $\begin{array}{l}\text { Mean } \\
\text { change in } \\
\text { the number } \\
\text { of IOP-low- } \\
\text { ering drops } \\
\text { instilled } \\
\text { per day } \\
\text { medi- } \\
\text { um-term fol- } \\
\text { low-up at } 24 \\
\text { months }\end{array}$ & $\begin{array}{l}\text { The mean change in the number of IOP- } \\
\text { lowering drops instilled per day in the } \\
\text { cataract surgery group was }-0.76 \text { drops }\end{array}$ & $\begin{array}{l}\text { The MD in the cataract surgery plus Hy- } \\
\text { drus group was } 0.41 \text { drops lower } \\
\text { ( } 0.56 \text { lower to } 0.27 \text { lower) }\end{array}$ & - & $\begin{array}{l}619 \\
\text { (2 RCTs) }\end{array}$ & $\begin{array}{l}\oplus \oplus \oplus \ominus \\
\text { Low }^{a, b}\end{array}$ \\
\hline & Proportion & Study population & & RR 0.17 & 619 & $\oplus \oplus \ominus \ominus$ \\
\hline 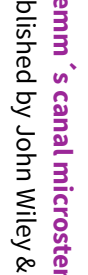 & $\begin{array}{l}\text { pants who } \\
\text { required } \\
\text { further } \\
\text { glaucoma } \\
\text { surgery, } \\
\text { including } \\
\text { laser }\end{array}$ & 25 per 1000 & $\begin{array}{l}4 \text { per } 1000 \\
(1 \text { to } 22)\end{array}$ & (0.03 to 0.86$)$ & & \\
\hline 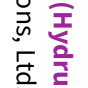 & $\begin{array}{l}\text { Visual field } \\
\text { progression }\end{array}$ & No data available & & & & \\
\hline $\begin{array}{l}\stackrel{0}{0} \\
\stackrel{0}{0} \\
\stackrel{0}{0} \\
\stackrel{0}{0} \\
\stackrel{0}{0} \\
\frac{00}{0} \\
00\end{array}$ & $\begin{array}{l}\text { Mean } \\
\text { change in } \\
\text { health-re- } \\
\text { lated quali- } \\
\text { ty of life }\end{array}$ & No data available & & & & \\
\hline 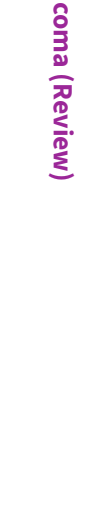 & $\begin{array}{l}\text { Proportion } \\
\text { of partici- } \\
\text { pants ex- } \\
\text { perienc- } \\
\text { ing intraop- } \\
\text { erative or } \\
\text { postopera- } \\
\text { tive compli- } \\
\text { cations } \\
\text { medi- } \\
\text { um-term fol- } \\
\text { low-up at } 24 \\
\text { months }\end{array}$ & $\begin{array}{l}\text { Intraoperative: device malposition (1.6 } \\
\text { (1.1\%) only occurred with Hydrus implar } \\
\text { Postoperative: Intraocular bleeding, los } \\
\mathrm{mmHg} \text { or more were rare in both groups } \\
\text { There were no cases of endophthalmitis }\end{array}$ & $\begin{array}{l}\text { or hyphaema obscuring the surgeons view } \\
\text { tion } \\
\text { f } 2 \text { or more VA lines, and IOP spikes of } 10 \\
\text { either group }\end{array}$ & & & $\begin{array}{l}\oplus \oplus \ominus \ominus \\
\text { Low }^{a, c}\end{array}$ \\
\hline
\end{tabular}




\begin{tabular}{|c|c|c|c|c|c|c|}
\hline \multicolumn{7}{|c|}{$\begin{array}{l}\text { *The risk in the intervention group (and its 95\% confidence interval) is based on the assumed risk in the comparison group and the rela } \\
\text { its } 95 \% \mathrm{CI}) \text {. } \\
\text { Cl: Confidence interval; IOP: intraocular pressure; MD: Mean difference; RR: Risk ratio; OR: Odds ratio; VA: visual acuity }\end{array}$} \\
\hline \multicolumn{7}{|c|}{$\begin{array}{l}\text { GRADE Working Group grades of evidence } \\
\text { High-certainty: We are very confident that the true effect lies close to that of the estimate of the effect } \\
\text { Moderate-certainty: We are moderately confident in the effect estimate: The true effect is likely to be close to the estimate of the effect, but there is a possibility that it is } \\
\text { substantially different } \\
\text { Low-certainty: Our confidence in the effect estimate is limited: The true effect may be substantially different from the estimate of the effect } \\
\text { Very low-certainty: We have very little confidence in the effect estimate: The true effect is likely to be substantially different from the estimate of effect }\end{array}$} \\
\hline \multicolumn{7}{|c|}{$\begin{array}{l}\text { aUnclear or high risk of bias for most domains (-1 for risk of bias) } \\
\text { bMean change in number of drops was calculated on about half of participants using } 2 \text { to } 4 \text { medications in HORIZON } 2018 \text { (-1 for indirectness) } \\
\text { cSmall number of events with imprecision (-1 for imprecision) }\end{array}$} \\
\hline \multicolumn{7}{|c|}{ Hydrus microstent compared to iStent trabecular micro-bypass stent } \\
\hline \multicolumn{7}{|c|}{$\begin{array}{l}\text { Patient or population: people with open angle glaucoma, many of whom had mild or moderate glaucoma, which was well-controlled with medication } \\
\text { Setting: eye clinics with surgical facilities } \\
\text { Intervention: Hydrus microstent (Hydrus) } \\
\text { Comparison: iStent trabecular micro-bypass stent (iStent) (n.2) }\end{array}$} \\
\hline \multirow[t]{2}{*}{ Outcomes } & \multicolumn{2}{|c|}{ Anticipated absolute effects ${ }^{*}(95 \% \mathrm{CI})$} & \multirow{2}{*}{$\begin{array}{l}\text { Relative ef- } \\
\text { fect } \\
(95 \% \mathrm{CI})\end{array}$} & \multirow{2}{*}{$\begin{array}{l}\text { No of partici- } \\
\text { pants } \\
\text { (studies) }\end{array}$} & \multirow{2}{*}{$\begin{array}{l}\text { Certainty of } \\
\text { the evidence } \\
\text { (GRADE) }\end{array}$} & \multirow[t]{2}{*}{ Comments } \\
\hline & Risk with iStent & Risk with Hydrus & & & & \\
\hline $\begin{array}{l}\text { Proportion of partici- } \\
\text { pants who were med- } \\
\text { ication-free (not using } \\
\text { eye drops) }\end{array}$ & Study population & & \multirow{2}{*}{$\begin{array}{l}\text { RR } 1.94 \\
\text { (1.21 to } 3.11)\end{array}$} & \multirow{2}{*}{$\begin{array}{l}148 \\
(1 \mathrm{RCT})\end{array}$} & \multirow{2}{*}{\multicolumn{2}{|c|}{$\begin{array}{l}\oplus \oplus \ominus \ominus \\
\text { Lowa,b }\end{array}$}} \\
\hline $\begin{array}{l}\text { ication-free (not using } \\
\text { eye drops) } \\
\text { short-term follow-up } \\
\text { at } 12 \text { months }\end{array}$ & 240 per 1000 & $\begin{array}{l}466 \text { per } 1000 \\
\text { ( } 290 \text { to } 746)\end{array}$ & & & & \\
\hline $\begin{array}{l}\text { Mean change in un- } \\
\text { medicated IOP (after } \\
\text { washout) }\end{array}$ & $\begin{array}{l}\text { The mean change in unmedicat- } \\
\text { ed IOP in the iStent group was }-5.1 \\
\mathrm{mmHg}\end{array}$ & $\begin{array}{l}\text { The MD in the Hydrus group was } \\
3.1 \text { lower } \\
\text { ( } 4.17 \text { lower to } 2.03 \text { lower) }\end{array}$ & - & $\begin{array}{l}148 \\
(1 \mathrm{RCT})\end{array}$ & $\begin{array}{l}\oplus \oplus \oplus \ominus \\
\text { Moderate } a\end{array}$ & \\
\hline
\end{tabular}




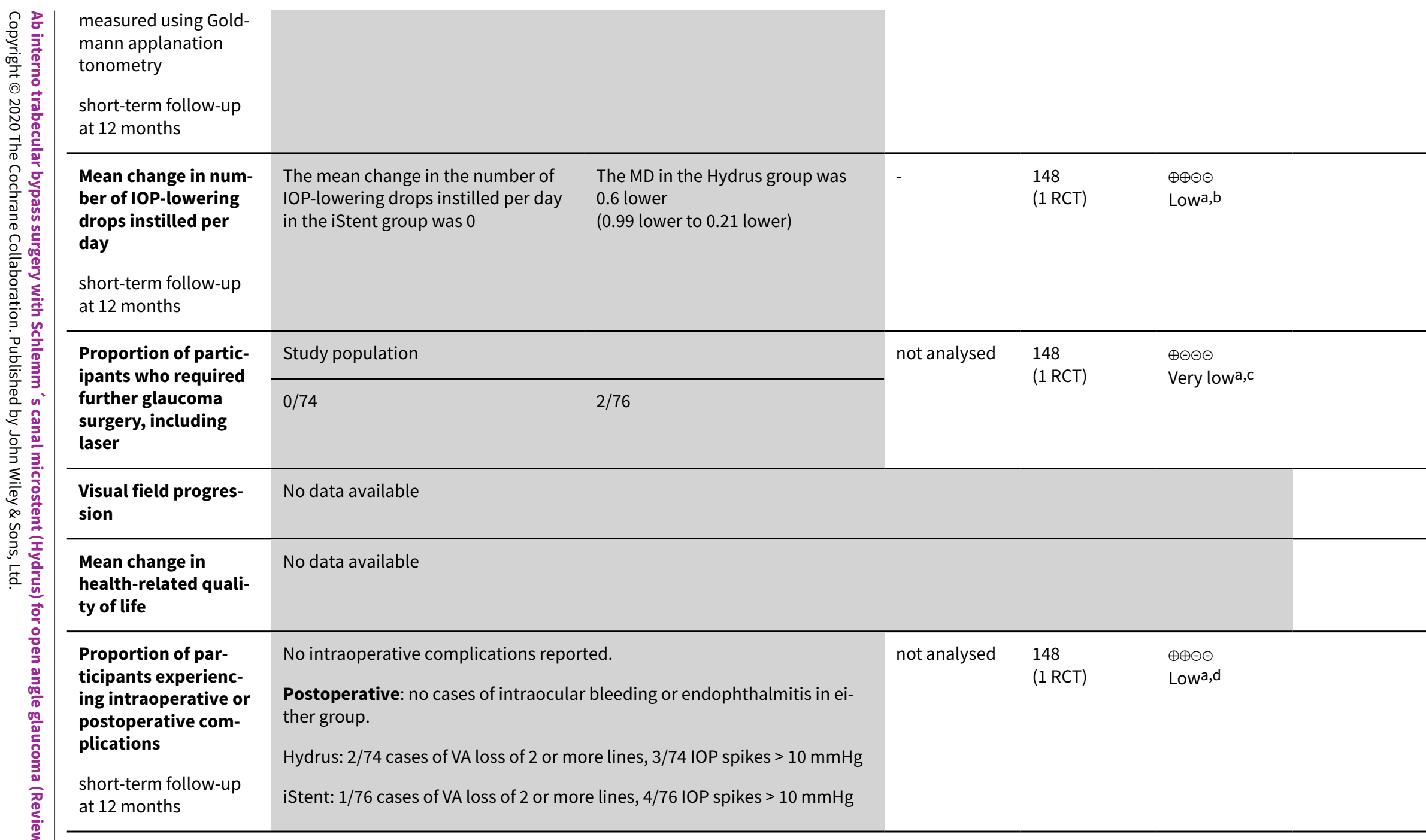

*The risk in the intervention group (and its $95 \%$ confidence interval) is based on the assumed risk in the comparison group and the relative effect of the intervention (and its $95 \% \mathrm{Cl}$ ).

CI: Confidence interval; IOP: intraocular pressure; MD: Mean difference; RR: Risk ratio; OR: Odds ratio

\section{GRADE Working Group grades of evidence}

High certainty: We are very confident that the true effect lies close to that of the estimate of the effect

Moderate certainty: We are moderately confident in the effect estimate: The true effect is likely to be close to the estimate of the effect, but there is a possibility that it is substantially different 
Low certainty: Our confidence in the effect estimate is limited: The true effect may be substantially different from the estimate of the effect

Very low certainty: We have very little confidence in the effect estimate: The true effect is likely to be substantially different from the estimate of effect

aUnmasked investigator

Large confidence intervals

cSparse data with no events in one study arm and only two events overall (-2 for imprecision)

dSmall number of events with imprecision (-1 for imprecision) 


\section{B A C K G R O U N D}

\section{Description of the condition}

Glaucoma is a chronic progressive optic neuropathy, affecting up to $4 \%$ of people by the age of 80 years (Burr 2007). It is the leading cause of irreversible blindness, affecting 60 million people globally (Quigley 2006). This figure is expected to increase to 80 million people by 2020. Open angle glaucoma (OAG) is the most common type, accounting for three-quarters of cases (Quigley 2006). In one large population cohort, one in six patients with OAG became bilaterally blind (Peters 2013). The only proven way to prevent vision loss is to reduce the pressure inside the eye (intraocular pressure) over the long term (AGIS 2000; CNTG Study Group 1998; Heijl 2002; Kass 2002; UKGTS 2015). Approaches to reducing intraocular pressure (IOP) include medical therapy, laser treatments, and surgery. Because commercially available eyedrop preparations have a short-lasting effect, medical therapy requires that eye-drops are instilled one or more times daily for life. Adherence is very poor, even if use is monitored (Friedman 2009; Okeke 2009). Conventional surgical techniques, such as trabeculectomy, are associated with significant risks, with more than $40 \%$ of patients developing perioperative complications (Kirwan 2013; Lichter 2001); reoperation is needed in $7 \%$ to $18 \%$ (Gedde 2012; Kirwan 2013). Therefore, surgery is often reserved for disease that is progressing despite other treatments (King 2013).

\section{Description of the intervention}

Recently, a number of minimally-invasive surgical techniques have been developed, with the aim of achieving long-term reduction of IOP, with a better safety profile than conventional surgery (Francis 2011). Among them, ab interno trabecular bypass surgery with a Schlemm 's canal Hydrus microstent (Ivantis Inc., Irvine, California) is marketed worldwide.

\section{How the intervention might work}

The trabecular meshwork is the main site of resistance to the outflow of aqueous humour from the eye (Overby 2009). The Hydrus microstent is an 8-mm long crescent-shaped open structure, curved to match the shape of the Schlemm's canal. This is intended to promote outflow of aqueous humour, and thereby reduce IOP. The microstent is implanted ab interno, through a clear corneal incision into the Schlemm's canal, using a preloaded handheld injector. After being implanted, the microstent bypasses the trabecular meshwork and dilates the Schlemm's canal over three clock hours, to provide direct aqueous access from the anterior chamber to multiple collector channels (Pfeiffer 2015).

\section{Why it is important to do this review}

Consultation with patients and healthcare professionals has identified a need for better treatments for glaucoma (James Lind Alliance 2013). Minimally-invasive glaucoma procedures carry the possibility of safe and effective long-term reduction of IOP, removing concerns about permanent vision loss due to nonadherence with eye-drops. A single treatment may also be more acceptable to patients than daily and indefinite self-administration of eye-drops. To date, approximately 17,000 treatments have been performed worldwide in either feasibility studies, randomised controlled trials, or data registries (Otarola 2019 [pers comm]). In light of the potential benefits for patients and the widespread uptake of the technique, it is important to critically evaluate the evidence for the efficacy and safety of treatment with the Hydrus microstent. Importantly, Hydrus microstent implantation surgery may be combined with phacoemulsification (cataract surgery, a sight-restoring operation to remove the natural lens of the eye when it has lost clarity). Since cataract surgery itself reduces IOP (Mansberger 2012), we will specifically examine the evidence for efficacy of Hydrus microstent treatment in people who have concomitant cataract surgery in comparison to those who do not have concomitant cataract surgery.

This Cochrane Review was conducted in parallel with other reviews undertaken by the Cochrane Eyes and Vision MIGS (minimallyinvasive glaucoma surgery) Consortium, which includes MIGS techniques and devices, such as the Trabectome (NeoMedix, Tustin, CA, USA (Hu 2016)), XEN Glaucoma Implant (AqueSys Implant, Aliso Viejo, CA, USA (King 2018)), endoscopic cytophotocoagulation (Endo Optiks, Waltham, MA, USA (Tóth 2019)), iStent and iStent inject (Glaukos Corporation, Laguna Hills, CA, USA (Le 2019)), and supraciliary microstent surgery (Sandhu 2017).

\section{O B JECTIVES}

To evaluate the efficacy and safety of ab interno trabecular bypass surgery with the Hydrus microstent in treating people with open angle glaucoma.

\section{METHODS}

\section{Criteria for considering studies for this review}

\section{Types of studies}

We included randomised controlled trials (RCTs) only. We included reports of RCTs prepared in any language, regardless of their publication status.

\section{Types of participants}

Participants had open angle glaucoma (OAG) of any type, including primary and secondary OAG. As there are no universally-accepted criteria by which glaucoma may be defined, we permitted studies to use their own definitions of glaucoma, provided these were clearly stated. We also included participants with ocular hypertension, normal tension glaucoma, or possible glaucoma (suspects for glaucoma).

We excluded trials with participants with closed angle glaucoma.

We did not apply any restrictions regarding location, setting, or demographics.

\section{Types of interventions}

We compared ab interno trabecular bypass surgery with the Hydrus microstent (Ivantis Inc., Irvine, California) to:

- laser treatment (selective laser trabeculoplasty or argon laser trabeculoplasty);

- other minimally-invasive glaucoma surgery (MIGS) techniques;

- conventional glaucoma surgery (trabeculectomy);

- medical therapy.

\section{Types of outcome measures}

We did not use the reporting of particular outcomes as a criterion for eligibility for the review. We did not exclude studies from the 
review solely on the grounds of not reporting an outcome of interest.

We reported outcomes in the short-term (six to 18 months), medium-term (18 to 36 months), and long-term (longer than 36 months).

\section{Primary outcomes}

- Proportion of participants who were medication-free (not using eye drops)

Several different glaucoma outcome measures have been specified as primary outcomes in other Cochrane Reviews and protocols (Ismail 2015). A recent study classified intraocular pressure (IOP), visual field, safety, and anatomic outcomes as being highly important to glaucoma experts (Ismail 2016). A panel of patients from the Patient and Public Involvement Group of the National Institute for Health Research (NIHR) Biomedical Research Centre for Ophthalmology identified drop-free disease control as a highly valued outcome (unpublished). We chose a participant-centred primary outcome.

\section{Secondary outcomes}

- Mean change in IOP, measured using Goldmann applanation tonometry

- Mean change in number of IOP-lowering drops taken per day

- Proportion of participants who achieved an IOP of $21 \mathrm{mmHg}$ or less

- Proportion of participants who achieved an IOP of $17 \mathrm{mmHg}$ or less

- Proportion of participants who achieved an IOP of $14 \mathrm{mmHg}$ or less

- Proportion of participants who required further glaucoma surgery, including laser, as recorded by the investigators of the included trial

- Rate of visual field progression (decibels (dB)/time) or proportion of participants whose field loss progressed in the follow-up period

- Mean change in health-related quality of life (HRQoL)

Adverse effects

- Proportion of participants experiencing intra- and postoperative complications, including, but not restricted to, the following:

- loss of visual acuity (more than 2 Snellen lines, or more than $0.3 \log M A R$, according to the method of recording visual acuity; or loss of light perception);

- bleeding, as recorded by the investigators;

- endophthalmitis, as recorded by the investigators;

- IOP spikes (postoperative rise in IOP, measured using Goldmann applanation tonometry, of more than 10 $\mathrm{mmHg}$ compared to the previous assessment, including measurements taken during the first postoperative month).

\section{Search methods for identification of studies}

\section{Electronic searches}

The Cochrane Eyes and Vision Information Specialist conducted systematic searches in the following electronic databases for RCTs and controlled clinical trials. There were no restrictions to language or year of publication. The date of the search was 7 May 2019.

- Cochrane Central Register of Controlled Trials (CENTRAL; 2019, Issue 5 (which contains the Cochrane Eyes and Vision Trials Register)) in the Cochrane Library (searched 7 May 2019; Appendix 1;

- MEDLINE Ovid (1946 to 7 May 2019; Appendix 2);

- Embase Ovid (1980 to 7 May 2019; Appendix 3);

- International Standard Research Clinical Trial Number (ISRCTN) registry (www.isrctn.com/editAdvancedSearch; searched 7 May 2019; Appendix 4);

- US National Institutes of Health Ongoing Trials Register ClinicalTrials.gov (www.clinicaltrials.gov; searched 7 May 2019; Appendix 5);

- World Health Organization (WHO) International Clinical Trials Registry Platform (ICTRP; www.who.int/ictrp; searched 7 May 2019; Appendix 6).

\section{Searching other resources}

We searched the reference lists of included studies for other possible studies, and contacted any individuals or organisations who conducted relevant RCTs. We also searched the website of the manufacturer (Ivantis Inc., Irvine, California; www.ivantisinc.com) for any information on forthcoming trials. We are awaiting additional data on included studies from the manufacturer.

\section{Data collection and analysis}

\section{Selection of studies}

Four review authors independently screened titles and abstracts of all articles identified by the search, using web-based online review management software (Covidence). If abstracts were not available, we screened full-text articles. Two review authors independently assessed the full-text reports of all potentially eligible studies. If there was disagreement regarding eligibility, a third review author arbitrated. If any full-text reports were rejected, we recorded the reasons for this.

\section{Data extraction and management}

We extracted data from reports of included studies using a data collection form, which was developed, but not piloted on the first five studies included as planned. Three review authors independently extracted study characteristics from reports of each study, and two review authors (AS, GV) entered the data for the studies into Review Manager 5 (RevMan 5 (Review Manager 2014)). Two review authors (GV, FO) independently extracted data for the analyses, and one review author (GV) checked the data, and then entered it into RevMan 5. If there was disagreement, a third review author arbitrated.

Data collected in Appendix 7 were presented in the 'Characteristics of included studies' table. Where data on included studies (or ongoing studies) were missing or unclear, we contacted the individuals or organisations involved to obtain clarification. We collected and used the most detailed numerical data available to facilitate analyses of included studies. We obtained these data from individuals or organisations in preference to less precise methods, such as extracting numeric data from graphs, as indicated. 


\section{Assessment of risk of bias in included studies}

We used the latest version of the Cochrane 'Risk of bias' tool, as described in Chapter 8 of the Cochrane Handbook for Systematic Reviews of Interventions to assess and judge the risk of bias for included studies (Higgins 2017).

\section{Measures of treatment effect}

We calculated the risk ratio for the following outcomes: proportion of participants who were medication-free (not using eye drops); proportion of participants who achieved an IOP of no more than 21 $\mathrm{mmHg}, 17 \mathrm{mmHg}$, and $14 \mathrm{mmHg}$; proportion of participants who required further glaucoma surgery; and proportion of participants who experienced intra- and postoperative complications.

When data were available, we calculated the mean difference for the following continuous outcomes: mean change in IOP; mean change in number of IOP-lowering drops instilled per day; and mean change in quality of life.

Where possible, we checked for the skewness of continuous data (Altman 1996).

\section{Unit of analysis issues}

We noted whether studies included one or two eyes from each participant, and whether randomisation was conducted at the level of the participant or the eye. There is a potential for medical treatments, such as topical beta blockers used for one eye, to influence the outcome in the other eye (Piltz 2000). Surgery to lower IOP in one eye may also affect the IOP of the fellow eye (Radcliffe 2010). Therefore, we excluded studies that had adopted a paired design.

\section{Dealing with missing data}

We tried to minimise missing outcome data by contacting individuals and organisations to obtain them. Because the level of missing data in each group and reasons for missing data in each group were similar, we analysed available case data. We are waiting for the manufacturer of the Hydrus microstent to provide us with unpublished data, which we will use in the update of this review.

\section{Assessment of heterogeneity}

We assessed the heterogeneity between trials by carefully examining the study reports, assessing forest plots, and examining the $I^{2}$ value. We considered $\mathrm{I}^{2}$ values greater than $50 \%$ to be indicative of substantial heterogeneity, suggesting that metaanalysis might not be wise. We also considered the consistency of the effect estimates. If all estimates were in the same direction, we pooled the data, even when heterogeneity was evident; we commented on any heterogeneity in the Discussion section.

\section{Assessment of reporting biases}

We planned to develop a funnel plot to assess the risk of publication bias if there were more than 10 trials in our review.

\section{Data synthesis}

We undertook a meta-analysis when data appeared clinically, methodologically, and statistically homogeneous. We checked that participants, interventions, comparators, and outcomes were sufficiently similar to give a clinically meaningful result, and that our $\mathrm{I}^{2}$ result did not indicate considerable inconsistency (i.e. $\mathrm{I}^{2}$ less than $50 \%$ ). In future updates of this review, we will pool heterogenous data if all estimates are in the same direction. We used a fixed-effect model, as there were fewer than three trials included in the meta-analyses.

\section{Subgroup analysis and investigation of heterogeneity}

We do not plan to conduct subgroup analyses in future updates of the review.

\section{Sensitivity analysis}

We planned to assess the impact of including studies at high risk of bias for an outcome in one or more key domains. However, there were too few included studies to conduct such analyses.

\section{Summary of findings and assessment of the certainty of the evidence}

We prepared tables to summarise the findings of the review, including the assessment of the certainty of evidence for all outcomes, using the GRADE approach (GRADEpro GDT).

We reported the following outcomes at medium-term followup (18 to 36 months) in the 'Summary of findings' table for each comparison listed in the Types of interventions: Ab interno trabecular bypass surgery with Schlemm's canal Hydrus microstent compared with laser treatment, other MIGS techniques, conventional glaucoma surgery (trabeculectomy), or medical therapy.

- Proportion of participants who were medication-free (not using eye drops).

- Mean change in IOP, measured using Goldmann applanation tonometry.

- Mean change in number of IOP-lowering drops taken per day.

- Proportion of participants who required further glaucoma surgery, including laser.

- Rate of visual field progression (decibels (dB)/time) or proportion of participants whose field loss progressed in the follow up period.

- Mean change in health-related quality of life.

- Proportion of participants experiencing intraoperative and postoperative complications (any time point).

\section{RE S U L T S}

\section{Description of studies}

\section{Results of the search}

The electronic searches yielded 713 records (Figure 1). After removing 115 duplicates, the Cochrane Information Specialist (CIS) screened the remaining 598 records, and removed 389 records that were not relevant to the scope of the review. We screened the remaining 209 records, and obtained the full-text reports of six records for further assessment. We included four reports of three studies (COMPARE 2019; HORIZON 2018; Pfeiffer 2015). We identified one ongoing study that met the inclusion criteria, and this will be assessed for inclusion in the review when data become available (NCT02024464). One study was a conference abstract (Altafini 2014). It was not clear whether this study collected data for outcomes of interest to this review. We have contacted the trial investigators and are awaiting a response. 
Figure 1. Study flow diagram

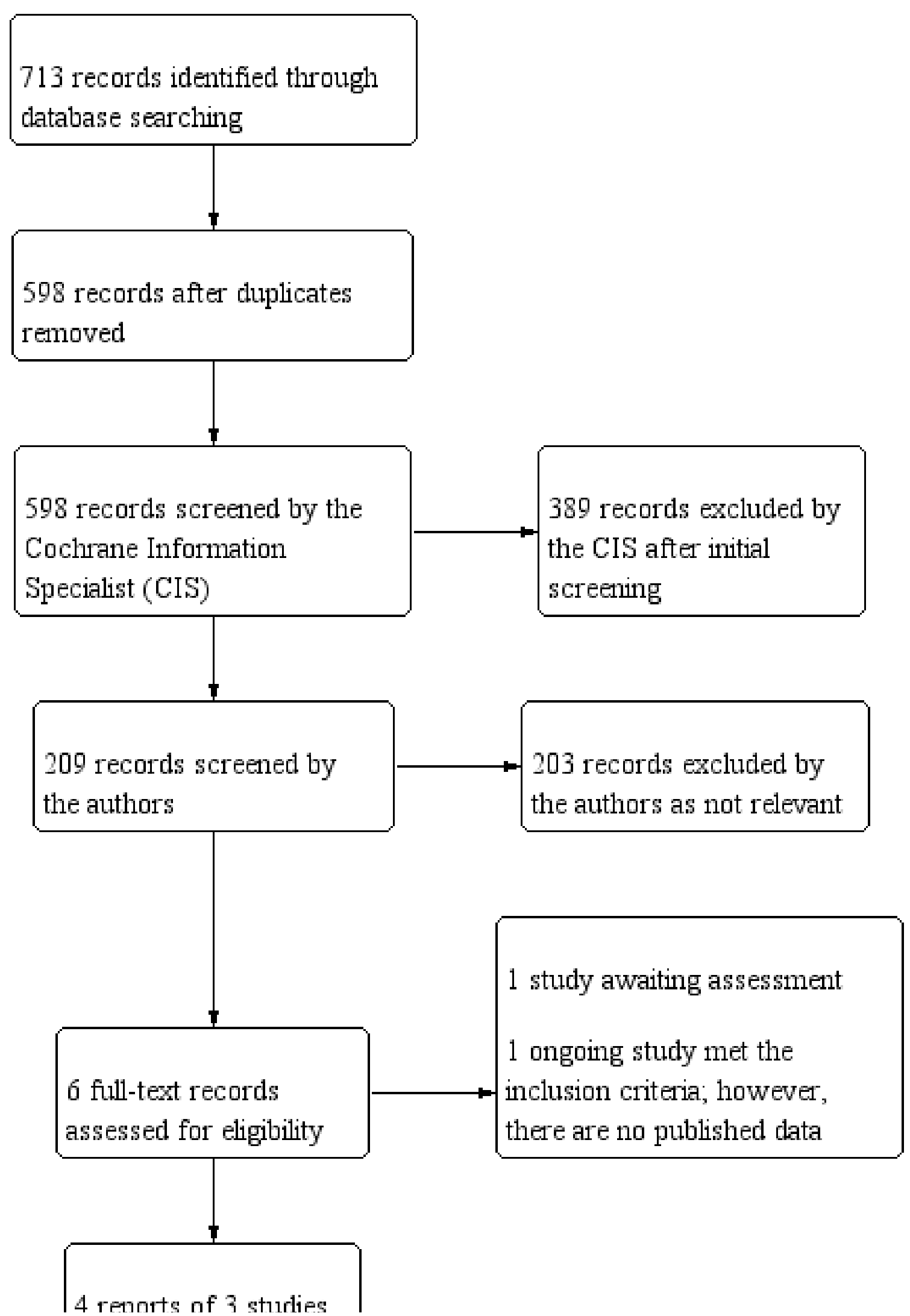


Figure 1. (Continued)

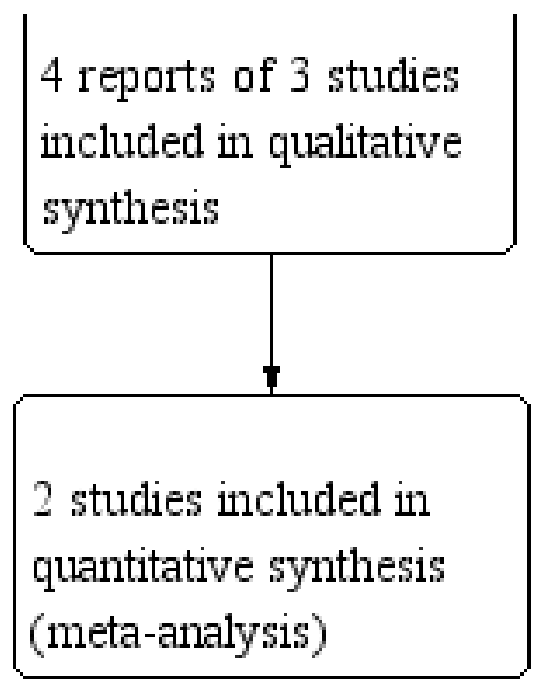

\section{Included studies}

We identified three studies that met our inclusion criteria. Two studies compared the Hydrus microstent with cataract surgery to cataract surgery alone in people with concurrent cataract and open angle glaucoma (OAG) (HORIZON 2018; Pfeiffer 2015). HORIZON 2018 was conducted at 26 sites in the United States and 12 international sites, and included 369 participants. Pfeiffer 2015 was a single-masked, multicentred randomised controlled trial (RCT) with 100 participants, based at several sites (Germany, Italy, Spain, and the Netherlands). COMPARE 2019 was a single-masked, multicentred RCT conducted at 12 sites in the United States and 8 international sites, which compared stand alone Hydrus microstent surgery to stand alone iStent (n.2 implants used in a single procedure) surgery in 152 participants.

All three studies were sponsored by the Hydrus manufacturer (Ivantis, Inc., Irvine, California).

In all studies, in the opinion of the investigators, participants had to be capable of safely undergoing medication wash-out. Pfeiffer 2015 included 100 participants, taking an average of two medications at baseline. At baseline, the Hydrus microstent with cataract surgery group had a mean medicated intraocular pressure (IOP) of 18.9 (SD 3.3) $\mathrm{mmHg}$ and mean deviation (MD) of -5.6 (SD 5.4) dB; the cataract surgery alone group had a mean medicated IOP of 18.6 (SD 3.8) $\mathrm{mmHg}$, and a MD of -8.4 (SD 7.8) dB.

HORIZON 2018 included participants with visually significant cataracts. At baseline, the Hydrus microstent with cataract surgery group had a mean medicated IOP of 17.9 (SD 3.1) $\mathrm{mmHg}$, took an average of 1.7 (SD 0.9) medications, and had a MD of -3.61 (SD 2.49) $\mathrm{dB}$; the cataract surgery alone group had a mean medicated IOP of 18.1 (SD 3.1) $\mathrm{mmHg}$, and a MD of -3.61 (SD 2.60) dB.
COMPARE 2019 included participants with phakic and pseudophakic (about $35 \%$ ) eyes with mostly mild or moderate OAG. At baseline, the Hydrus microstent group had a mean medicated IOP of 19.0 (SD 3.9) $\mathrm{mmHg}$, were on an average of 2.5 (SD 0.7) medications, and had a MD of 6.2 (SD 5.4) dB; the iStent group had a mean medicated IOP of 19.1 (SD 3.6) $\mathrm{mmHg}$, were on an average of 2.7 (SD 0.8) medications, and had a MD of 6.2 (SD 6.5) dB.

The type of participants included in the trials suggests that many of these participants had medically-controlled glaucoma. See Characteristics of included studies for further information.

\section{Ongoing studies}

We identified one ongoing study that met our inclusion criteria, which compares the Hydrus microstent with the iStent trabecular micro-bypass stent (NCT02024464). See Characteristics of ongoing studies table for further information.

\section{Studies awaiting classification}

We have placed one conference abstract (Altafini 2014), in Studies awaiting classification as it is not clear whether this study collected data for outcomes of interest to this review. We have contacted the trial investigators and are awaiting a response.

\section{Excluded studies}

We did not exclude any studies.

\section{Risk of bias in included studies}

See Figure 2 
Figure 2. Risk of bias summary: review authors' judgements about each risk of bias item for each included study

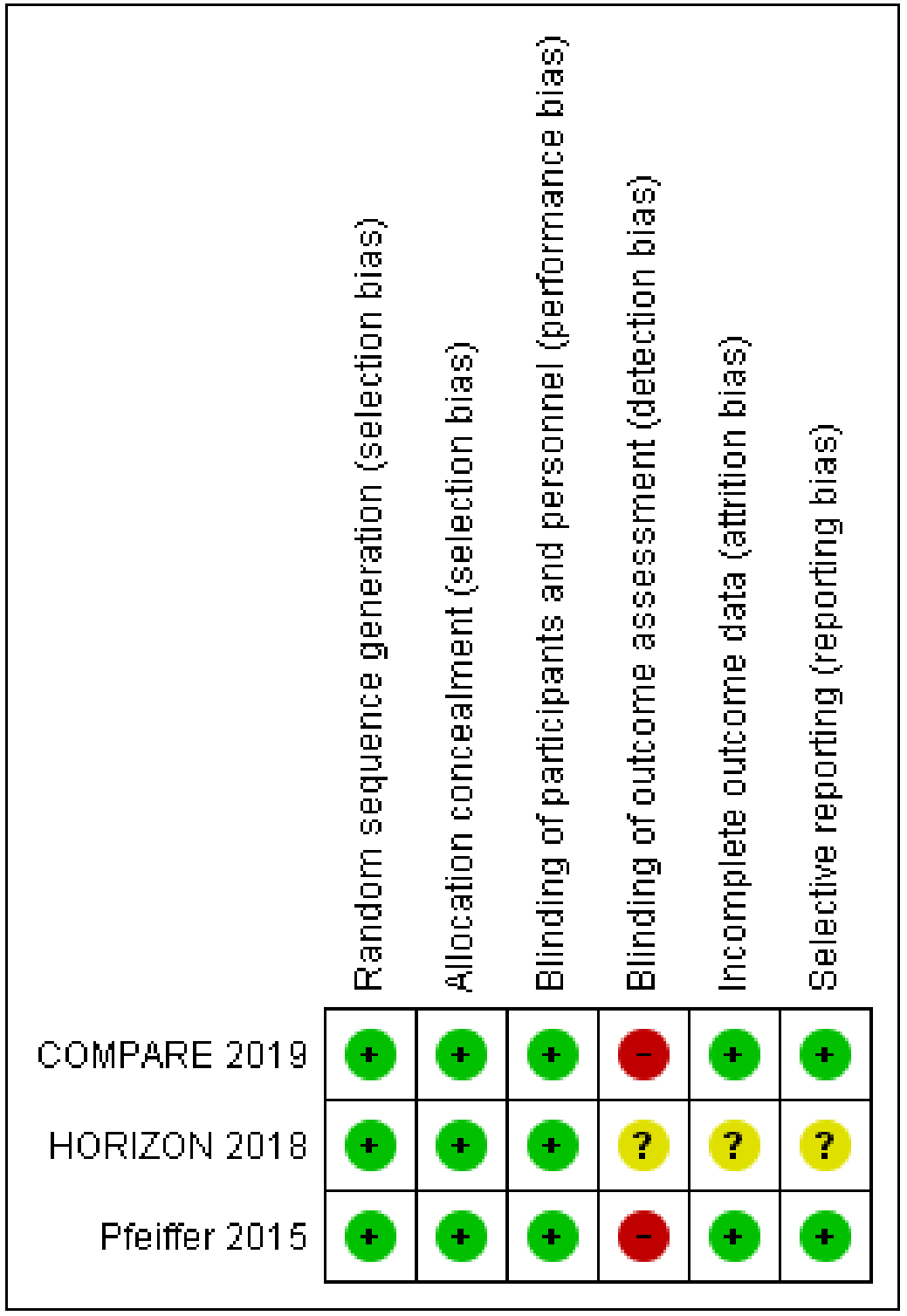

\section{Allocation}

Random sequence generation and allocation concealment were adequate in all studies.

\section{Blinding}

Participants and personnel were masked to intervention assignment, but masking of outcome assessors was unclear or high risk in all studies.

\section{Incomplete outcome data}

HORIZON 2018 reported that 5\% of participants were lost at 24 months, but the proportion and causes in each study arm was not reported. Pfeiffer 2015 reported that at 24 months, 3 out of 50 participants from the Hydrus microstent plus cataract surgery group and 7 out of 50 participants from the cataract surgery group were missing; for those with unmedicated IOP, 6 out of 50 from the Hydrus microstent plus cataract surgery group and 16 out of 50 from the cataract surgery group were missing. We considered both studies at unclear risk of bias for this domain. Only two participants in each group were lost to follow-up in COMPARE 2019.

\section{Selective reporting}

We could not obtain a study protocol to check extensively for selection bias, but there seemed to be no major difference compared to the information found on ClinicalTrials.gov.

\section{Other potential sources of bias}

No other sources of bias were identified.

\section{Effects of interventions}

See: Summary of findings for the main comparison Cataract surgery with Hydrus microstent compared to cataract surgery alone; Summary of findings 2 Hydrus microstent compared to iStent trabecular micro-bypass stent

Ab interno trabecular bypass surgery with Schlemm 's canal microstent (Hydrus) for open angle glaucoma (Review) 
Hydrus microstent with cataract surgery versus cataract surgery alone

See Summary of findings for the main comparison for a summary of all available results.

\section{Proportion of participants who were medication-free (not using eye drops)}

The Hydrus microstent with cataract surgery increased the proportion of participants who were medication-free, both at short-term follow-up (risk ratio (RR) 1.59, 95\% confidence interval (Cl) 1.39 to 1.83 ; 2 studies, 639 participants; $I^{2}=0 \%$; moderatecertainty evidence, due to risk of bias; Analysis 1.1; Figure 3), and at medium-term follow-up (RR $1.63,95 \% \mathrm{Cl} 1.40$ to $1.88 ; 2$ studies, 619 participants; moderate-certainty evidence, due to risk of bias; Analysis 1.2; Figure 4).

Figure 3. Forest plot of comparison: 1 Cataract surgery with Hydrus microstent vs. cataract surgery (CS) alone, outcome: 1.1 Proportion drop-free: short term

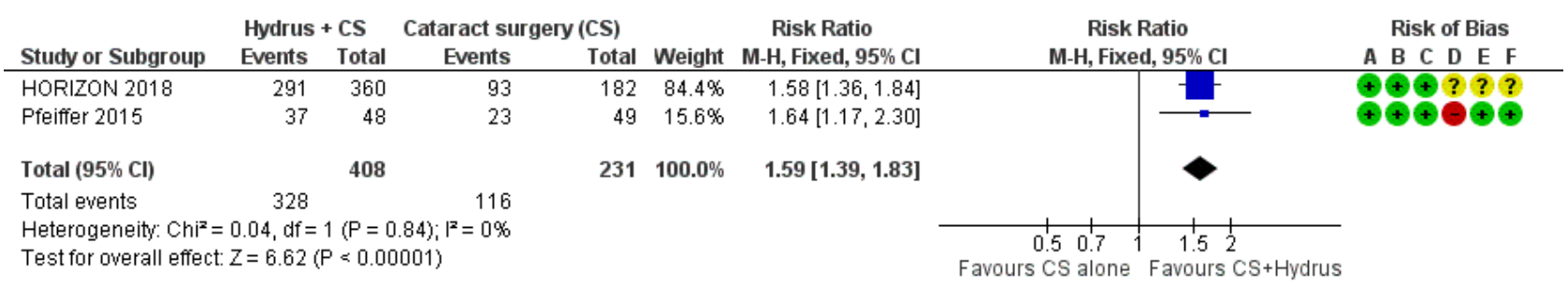

Risk of bias legend

(A) Random sequence generation (selection bias)

(B) Allocation concealment (selection bias)

(C) Blinding of participants and personnel (performance bias)

(D) Blinding of outcome assessment (detection bias)

(E) Incomplete outcome data (attrition bias)

(F) Selective reporting (reporting bias)

Figure 4. Forest plot of comparison: 1 Cataract surgery with Hydrus microstent vs cataract surgery (CS) alone, outcome: 1.2 Proportion drop-free: medium term

\begin{tabular}{|c|c|c|c|c|c|c|c|c|c|}
\hline \multirow[b]{2}{*}{ Study or Subgroup } & \multicolumn{2}{|c|}{ Hydrus + CS } & \multicolumn{2}{|c|}{ Cataract surgery (CS) } & \multirow[b]{2}{*}{ Weight } & \multirow{2}{*}{$\begin{array}{c}\text { Risk Ratio } \\
\text { M-H, Fixed, } 95 \% \mathrm{CI}\end{array}$} & \multirow{2}{*}{\multicolumn{2}{|c|}{$\begin{array}{c}\text { Risk Ratio } \\
\text { M-H, Fixed, } 95 \% \mathrm{Cl}\end{array}$}} & Risk of Bias \\
\hline & Events & Total & Events & Total & & & & & A B C D E F \\
\hline HORIZON 2018 & 273 & 351 & 85 & 178 & $83.7 \%$ & $1.63[1.38,1.92]$ & & & †૯૯? ? ? \\
\hline Pfeiffer 2015 & 37 & 47 & 21 & 43 & $16.3 \%$ & $1.61[1.15,2.26]$ & & & 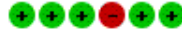 \\
\hline Total $(95 \% \mathrm{Cl})$ & & 398 & & 221 & $100.0 \%$ & $1.63[1.40,1.88]$ & & & \\
\hline Total events & 310 & & 106 & & & & & & \\
\hline $\begin{array}{l}\text { Heterogeneity: } \mathrm{Chi}^{2}= \\
\text { Test for overall effect }\end{array}$ & $\begin{array}{l}0.00, d f= \\
Z=6.450\end{array}$ & $\begin{array}{l}1(P=0 \\
P<0.00\end{array}$ & $\begin{array}{l}1.96) ;\left.\right|^{2}=0 \% \\
0001)\end{array}$ & & & & $\begin{array}{cc}0.5 & 0.7 \\
\text { Favours CS alone }\end{array}$ & 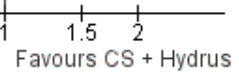 & \\
\hline $\begin{array}{l}\text { Risk of bias leqend } \\
\text { (A) Random sequen } \\
\text { (B) Allocation concea } \\
\text { (C) Blinding of partici } \\
\text { (D) Blinding of outcor } \\
\text { (E) Incomplete outco } \\
\text { (F) Selective reportin }\end{array}$ & $\begin{array}{l}\text { e generat } \\
\text { ment (sel } \\
\text { ants and } \\
\text { he assess } \\
\text { he data (a } \\
\text { (reportin }\end{array}$ & $\begin{array}{l}\text { ion (sel } \\
\text { ection b } \\
\text { person } \\
\text { ment ( } c \\
\text { ttrition b } \\
\text { bias) }\end{array}$ & $\begin{array}{l}\text { lection bias) } \\
\text { ias) } \\
\text { nel (performa } \\
\text { detection bias } \\
\text { oias) }\end{array}$ & ias) & & & & & \\
\hline
\end{tabular}

\section{Mean change in intraocular pressure (IOP) measured using Goldmann applanation tonometry}

The Hydrus microstent with cataract surgery reduced unmedicated IOP by an additional $2 \mathrm{mmHg}$ (mean difference (MD) $-2.00 \mathrm{mmHg}$,
$95 \% \mathrm{Cl}-2.69$ to $-1.31 \mathrm{mmHg} ; 2$ studies, 619 participants; $\mathrm{I}^{2}=0 \%$; moderate-certainty evidence, due to risk of bias; Analysis 1.3; Figure 5). Not all participants in Pfeiffer 2015 underwent washout, but given their small number and the small weight of the study in the analysis, we did not downgrade this evidence further. 
Figure 5. Forest plot of comparison: 1 Cataract surgery with Hydrus microstent vs cataract surgery (CS) alone, outcome: 1.4 Mean change in IOP-lowering drops taken per day: medium term

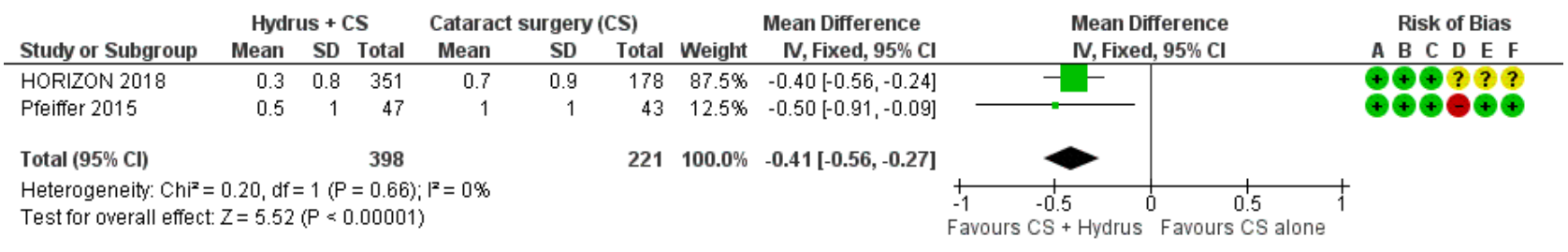

Risk of bias legend

(A) Random sequence generation (selection bias)

(B) Allocation concealment (selection bias)

(C) Blinding of participants and personnel (performance bias)

(D) Blinding of outcome assessment (detection bias)

(E) Incomplete outcome data (attrition bias)

(F) Selective reporting (reporting bias)

We were only able to obtain medium-term data on unmedicated IOP (after washout); there were no data available at 12 months, or for medicated IOP (medication needed) at any follow-up. We expected the difference in medicated IOP to be smaller between intervention groups, because the number of medications during follow-up was higher in the cataract surgery only group in both studies. The standard deviation of IOP change for Pfeiffer 2015 was not reported, so we imputed it from HORIZON 2018.
Mean change in number of IOP-lowering medications taken per day

The Hydrus microstent combined with cataract surgery increased the proportion of participants (MD $-0.41,95 \% \mathrm{Cl}-0.56$ to -0.27 ; 2 studies, 619 participants; $I^{2}=0 \%$; Analysis 1.4; Figure 6; lowcertainty of evidence due to risk of bias and indirectness).

Figure 6. Forest plot of comparison: 1 Cataract surgery with Hydrus microstent vs cataract surgery (CS) alone, outcome: 1.3 Mean change in IOP measured using Goldmann applanation tonometry: medium term

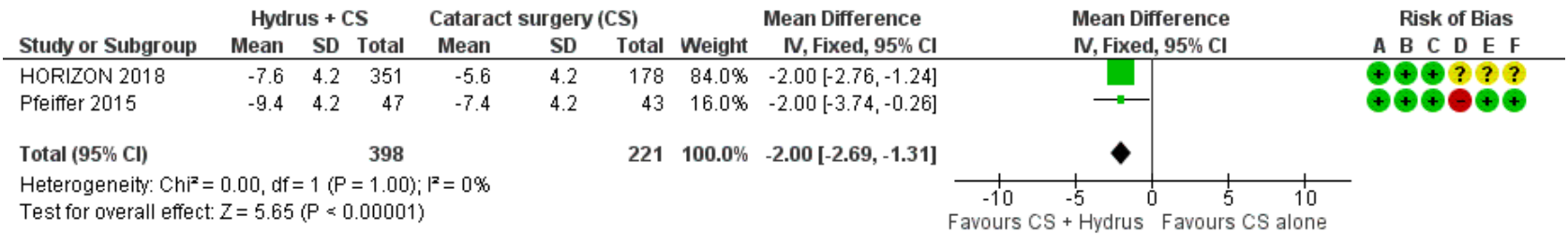

\footnotetext{
Risk of bias legend

(A) Random sequence generation (selection bias)

(B) Allocation concealment (selection bias)

(C) Blinding of participants and personnel (performance bias)

(D) Blinding of outcome assessment (detection bias)

(E) Incomplete outcome data (attrition bias)

(F) Selective reporting (reporting bias)
}

We were only able to obtain medium-term data. Not all participants in Pfeiffer 2015 underwent washout; in HORIZON 2018, about half of the participants were taking two to four medications at baseline, which led us to downgrade this evidence for indirectness, since this was the largest trial in the analysis.

Proportion of participants who achieved an IOP of $21 \mathrm{mmHg}, 17$ $\mathrm{mmHg}$, and $14 \mathrm{mmHg}$ or less

There were no data for this outcome.

Proportion of participants who required further glaucoma surgery, including laser, as recorded by the investigators of the included trial

Fewer surgeries were needed for the Hydrus microstent combined with cataract surgery group compared with the cataract surgery alone group, but this analysis was based on only seven events (RR $0.17,95 \% \mathrm{Cl} 0.03$ to $0.86 ; 2$ studies, 653 participants; $\left.\right|^{2}=27 \%$; lowcertainty evidence, due to risk of bias and imprecision; Analysis 1.5).
Rate of visual field progression (decibel (dB)/time), or proportion of participants whose field loss progressed in the follow-up period

There were no data for this outcome.

\section{Mean change in health-related quality of life (HRQOL)}

None of the studies measured health-related quality of life.

\section{Proportion of participants experiencing intra- and postoperative complications}

Only HORIZON 2018 reported intraoperative complications. Device malposition $(1.6 \%)$ or hyphaema obscuring the surgeons' view (1.1\%) occurred only with Hydrus microstent implantation. We judged this evidence to be very low-certainty, due to risk of bias (-1) and imprecision (-2). 
Among postoperative complications, intraocular bleeding, loss of 2 or more visual acuity (VA) lines, IOP spikes of $10 \mathrm{mmHg}$ or more were rare in both groups, and estimates were very imprecise (Analysis 1.6; Analysis 1.7; Analysis 1.8). There were no cases of endophthalmitis in either group. We judged this evidence to be very low-certainty, due to risk of bias (-1) and imprecision (-2).

\section{Hydrus microstent versus iStent trabecular micro-bypass stent}

Only one study provided short-term data for this comparison (Summary of findings 2; COMPARE 2019).

\section{Proportion of participants who were medication-free (not using eye drops)}

The Hydrus microstent increased the proportion of medicationfree participants from about $24 \%$ to $46.6 \%$ compared to the iStent trabecular micro-bypass stent, but this estimate was imprecise (RR $1.94,95 \% \mathrm{Cl} 1.21$ to 3.11 ; 1 study, 146 participants; low-certainty evidence, due to risk of bias and imprecision; Analysis 2.1).

\section{Mean change in IOP measured using Goldmann applanation tonometry}

COMPARE 2019 did not provide data on medicated IOP (eye drops needed); we expected the difference in medicated IOP to be smaller between intervention groups, because the number of medications during follow-up was higher in the iStent group. The Hydrus microstent reduced unmedicated IOP (after wash-out) by about $3 \mathrm{mmHg}$ more than the iStent trabecular micro-bypass stent (MD $-3.10,95 \% \mathrm{Cl}-4.17$ to -2.03 ; 1 study, 148 participants; moderatecertainty of evidence, due to risk of bias; Analysis 2.2); the latter achieved a reduction of about $5 \mathrm{mmHg}$.

\section{Mean change in number of IOP-lowering drops taken per day}

The Hydrus microstent reduced IOP-lowering medication by one daily medication compared to the iStent trabecular micro-bypass stent (MD $-0.60,95 \% \mathrm{Cl}-0.99$ to $-0.21 ; 1$ study, 148 participants; lowcertainty of evidence due to risk of bias and imprecision; Analysis 2.3).

\section{Proportion of participants who achieved an IOP of $21 \mathrm{mmHg}, 17$ $\mathrm{mmHg}$, and $14 \mathrm{mmHg}$ or less}

We extracted the proportion of participants achieving IOP $<21$ $\mathrm{mmHg}$, which was high for both the Hydrus microstent $(91.8 \%)$ and the iStent trabecular micro-bypass stent (84\%); no evidence of difference was found (RR: $1.09,95 \% \mathrm{Cl} 0.97$ to $1.23 ; 1$ study, 148 participants; low-certainty of evidence, due to risk of bias and imprecision; Analysis 2.4).

\section{Proportion of participants who required further glaucoma surgery, including laser, as recorded by the investigators of the included trial}

None of the 74 participants with the Hydrus microstent needed further surgery compared to 2 out of 76 with the iStent trabecular micro-bypass stent. We did not conduct a formal comparison due to sparse data.

\section{Rate of visual field progression (dB/time) or proportion of participants whose field loss progressed in the follow-up period}

There were no data for this outcome.

\section{Mean change in health-related quality of life}

There were no data for this outcome.

\section{Proportion of participants experiencing intra- and postoperative complications}

Few adverse events were seen in either group in COMPARE 2019. The Hydrus microstent group reported 2/74 cases of VA loss of 2 or more lines and $3 / 74$ IOP spikes $>10 \mathrm{mmHg}$, while the iStent trabecular micro-bypass stent group reported $1 / 76$ cases of VA loss of 2 or more lines, and 4/76 IOP spikes $>10 \mathrm{mmHg}$. There were no cases of bleeding or endophthalmitis in either group. We did not conduct a formal comparison due to sparse data.

\section{DISCUSSION}

\section{Summary of main results}

We found moderate-certainty evidence at short- and mediumterm follow-up that in people with cataracts and mainly mild or moderate open angle glaucoma (OAG), which was often wellcontrolled with medication, the Hydrus microstent combined with cataract surgery may increase the proportion of people who are medication-free, and decrease the average unmedicated intraocular pressure (IOP) by about $2 \mathrm{mmHg}$ compared to cataract surgery alone. We found low-certainty evidence that the Hydrus microstent may also decrease the number of medications and the need for secondary glaucoma surgery, without increasing postoperative complications.

We found low-certainty evidence from a single trial that compared to the insertion of the iStent trabecular micro-bypass stent, the Hydrus microstent may increase the proportion of medication-free participants from about a quarter to about a half, and moderatecertainty evidence that the Hydrus microstent may further reduce the unmedicated IOP by about $3 \mathrm{mmHg}$, while decreasing the number of medications. Participants included in this study were also often affected by medically-controlled, mild or moderate glaucoma.

\section{Overall completeness and applicability of evidence}

Because we only included three studies, with specific inclusion criteria, the results of our review may not be applicable to different glaucoma populations, especially to people with medically uncontrolled or severe glaucoma. Furthermore, the included studies did not provide data on long-term efficacy, or visual field progression.

\section{Quality of the evidence}

The certainty of the evidence was generally moderate or low, due to risk of bias and imprecision of many of the estimates. Risk of bias was also due to lack of masking of the treating physician and outcome assessor, which could influence the decision to prescribe medications or further surgery. Finally, we remark that unmedicated IOP is a measure of efficacy with respect to medicated IOP, as measured in practice, which is a measure of effectiveness. As stated in the 'Effects of interventions' section, we expected the difference in medicated IOP to be smaller between intervention groups, because the number of medications during follow-up was higher in the control group, due to the fact that more eye drops are used when target IOP is not achieved. 
The protocol for this review aimed to include studies on participants with medically uncontrolled OAG (Otarola 2017). However, all trials were conducted on a mixed population, including many participants with mild to moderate medically controlled OAG. We did not downgrade the certainty of the evidence for indirectness, since this evidence was still useful to evaluate the efficacy and safety of ab interno trabecular bypass surgery with a Hydrus microstent in people with OAG. Of interest, a posthoc analysis of HORIZON 2018 was conducted on data from the USA sites (about $60 \%$ of the total sample size), which found that unmedicated IOP reduction was achieved, and was possibly greater in participants with a baseline IOP over $26 \mathrm{mmHg}$, compared to 24 $\mathrm{mmHg}$ or less.

All studies obtained visual field testing at baseline, but this was not reported at one or two years.

\section{Potential biases in the review process}

Our literature search was systematic, and we contacted the authors of the included studies to obtain additional information, which is still outstanding. However, we decided to publish the review with the available published evidence, and will update it when further data are received from authors and study sponsors.

\section{Agreements and disagreements with other studies or reviews}

Lavia 2017 and Agrawal 2018 conducted systematic reviews on several minimally-invasive glaucoma surgery (MIGS) devices, which included both randomised and non-randomised studies. Both reviews included Pfeiffer 2015 and concluded that insufficient evidence from RCTs was available on the Hydrus microstent.

\section{AUTHORS' CONCLUSIONS}

\section{Implications for practice}

When added to cataract surgery, the Hydrus microstent may improve the intraocular pressure (IOP)-lowering effect of cataract surgery alone, and increase the proportion of participants who are medication-free from one half to about three quarters. However, short- and medium-term data were available from only two studies, which did not report on IOP change with eye drops, as is done in practice. The Hydrus microstent is more effective than the implantation of two iStent trabecular bypass stents. Few complications were found with the Hydrus microstent, but events were rare and their frequency was not precisely estimated. All included studies were sponsored by the Hydrus manufacturer Ivantis Inc.

This evidence was obtained from a mixed population of participants with mild or moderate open angle glaucoma (OAG), medically controlled OAG; its applicability to selected participants with severe or uncontrolled OAG should be further investigated.

\section{Implications for research}

More studies are needed: in different populations, with direct comparisons to medical treatment and selective laser trabeculoplasty, and between minimally-invasive glaucoma surgery devices. Studies should report medicated IOP change. Studies should be conducted for the long-term, and selectively in participants with medically uncontrolled glaucoma. Although little short- and medium-term visual field changes are expected in mild to moderate OAG, visual field testing should be reported as an outcome measure and results made available.

\section{ACK N O WLEDGEMENTS}

Cochrane Eyes and Vision (CEV) created and executed the electronic search strategies. We thank Nitin Anand and Jennifer Evans for their comments on the published protocol that forms the template for this one (Hu 2016).

We thank the members of the MIGS Consortium for their input in this review. 


\section{RE F E R E N C E S}

\section{References to studies included in this review}

COMPARE 2019 \{published data only\}

* Ahmed IIK, Fea A, Au L, Ang RE, Harasymowycz P, Jampel H, et al. A prospective randomized trial comparing Hydrus and iStent micro-invasive glaucoma surgery implants for standalone treatment of open-angle glaucoma: the COMPARE Study. Ophthalmology 2019;18:S0161-6420.

\section{HORIZON 2018 \{published data only\}}

Jones J, Koch DD, Vold S, McCabe C, Rhee D, Lewis R, et al. Results from the United States cohort of the HORIZON trial of a Schlemm canal microstent to reduce intraocular pressure in primary open-angle glaucoma. Journal of Cataract and Refractive Surgery 2019;45(9):1305-15.

Samuelson TW, Chang DF, Marquis R, Flowers B, Lim KS, Ahmed IIK, et al. A Schlemm canal microstent for intraocular pressure reduction in primary open-angle glaucoma and cataract: the HORIZON study. Ophthalmology 2018;126(1):29-37.

\section{Pfeiffer 2015 \{published data only\}}

Pfeiffer N, Garcia-Feijoo J, Martinez-de-la-Casa JM, Larrosa JM, Fea A, Lemij $\mathrm{H}$, et al. A randomized trial of a Schlemm's canal microstent with phacoemulsification for reducing intraocular pressure in open-angle glaucoma. Ophthalmology 2015;122(7):1283-93.

\section{References to studies awaiting assessment}

Altafini 2014 \{published data only (unpublished sought but not used)\}

Altafini R, Fea AM, Morselli S, Grignolo FM. Comparison between endothelial cell loss after express implant and mics, phaco mics safe-trabeculectomy and phaco with hydrus implant. Investigative Ophthalmology and Visual Science 2014; Vol. 55:ARVO E-abstract 6127.

\section{References to ongoing studies}

NCT02024464 \{published data only\}

NCT02024464. Comparing Hydrus microstent (TM) to the iStent for lowering IOP in glaucoma patients undergoing cataract surgery. clinicaltrials.gov/ct2/show/NCT02024464 (first received 20 December 2013)

\section{Additional references}

\section{AGIS 2000}

AGIS. The Advanced Glaucoma Intervention Study (AGIS): 7. The relationship between control of intraocular pressure and visual field deterioration. American Journal of Ophthalmology 2000;130(4):429-40.

\section{Agrawal 2018}

Agrawal P, Bradshaw SE. Systematic literature review of clinical and economic outcomes of micro-invasive glaucoma surgery
(MIGS) in primary open-angle glaucoma. Ophthalmology and Therapy 2018;7(1):49-73.

\section{Altman 1996}

Altman DG, Bland JM. Detecting skewness from summary information. BMJ 1996;313(7066):1200.

\section{Burr 2007}

Burr JM, Mowatt G, Hernandez R, Siddiqui MA, Cook J, Lourenco T, et al. The clinical effectiveness and costeffectiveness of screening for open angle glaucoma: a systematic review and economic evaluation. Health Technology Assessment 2007;11(41):1-190.

\section{CNTG Study Group 1998}

CNTG Study Group. Comparison of glaucomatous progression between untreated patients with normal-tension glaucoma and patients with therapeutically reduced intraocular pressures. American Journal of Ophthalmology 1998;126(4):487-97.

\section{Covidence [Computer program]}

Veritas Health Innovation. Covidence. Melbourne: Veritas Health Innovation, accessed prior to 9 September 2018.

\section{Francis 2011}

Francis BA, Singh K, Lin SC, Hodapp E, Jampel HD, Samples JR, et al. Novel glaucoma procedures: a report by the American Academy of Ophthalmology. Ophthalmology 2011;118(7):1466-80.

\section{Friedman 2009}

Friedman DS, Okeke CO, Jampel HD, Ying GS, Plyler RJ, Jiang Y, et al. Risk factors for poor adherence to eyedrops in electronically monitored patients with glaucoma. Ophthalmology 2009;116(6):1097-105.

\section{Gedde 2012}

Gedde SJ, Herndon LW, Brandt JD, Budenz DL, Feuer WJ, Schiffman JC, et al. Postoperative complications in the Tube Versus Trabeculectomy (TVT) study during five years of followup. American Journal of Ophthalmology 2012;153(5):804-14

\section{Glanville 2006}

Glanville JM, Lefebvre C, Miles JN, Camosso-Stefinovic J. How to identify randomized controlled trials in MEDLINE: ten years on. Journal of the Medical Library Association 2006;94(2):130-6.

\section{GRADEpro GDT [Computer program]}

McMaster University (developed by Evidence Prime). GRADEpro GDT. Version accessed prior to 24 April 2019. Hamilton (ON): McMaster University (developed by Evidence Prime).

\section{Heijl 2002}

Heijl A, Leske MC, Bengtsson B, Hyman L, Bengtsson B, Hussein $M$, et al. Reduction of intraocular pressure and glaucoma progression: results from the Early Manifest Glaucoma Trial. Archives of Ophthalmology 2002;120(10):1268-79. 


\section{Higgins 2017}

Higgins JPT, Altman DG, Sterne JAC, editor(s). Chapter 8: Assessing risk of bias in included studies. In: Higgins JP, Churchill R, Chandler J, Cumpston MS, editor(s), Cochrane Handbook for Systematic Reviews of Interventions version 5.2.0 (updated June 2017). The Cochrane Collaboration, 2017. Available from www.training.cochrane.org/handbook.

\section{Hu 2016}

Hu K, Gazzard G, Bunce C, Wormald R. Ab interno trabecular bypass surgery with Trabectome for open angle glaucoma. Cochrane Database of Systematic Reviews 2016, Issue 8. [DOI: 10.1002/14651858.CD011693.pub2]

\section{Ismail 2015}

Ismail R, Azuara-Blanco A, Ramsay CR. Outcome measures in glaucoma: a systematic review of Cochrane Reviews and protocols. Journal of Glaucoma 2015;24(7):533-8.

\section{Ismail 2016}

Ismail R, Azuara-Blanco A, Ramsay CR. Consensus on outcome measures for glaucoma effectiveness trials: results from a Delphi and nominal group technique approaches. Journal of Glaucoma 2016;25(6):539-46.

\section{James Lind Alliance 2013}

James Lind Alliance Sight Loss, Vision Priority Setting Partnership. Setting priorities for eye research. www.jla.nihr.ac.uk > downloads > SLV-PSP_Final_Report_v111 (accessed 15 November 2019).

\section{Kass 2002}

Kass MA, Heuer DK, Higginbotham EJ, Johnson CA, Keltner JL, Miller JP, et al. The Ocular Hypertension Treatment Study: a randomized trial determines that topical ocular hypotensive medication delays or prevents the onset of primary open-angle glaucoma. Archives of Ophthalmology 2002;120(6):701-13.

\section{King 2013}

King A, Azuara-Blanco A, Tuulonen A. Glaucoma. BMJ 2013;346:\{3518.

\section{King 2018}

King AJ, Shah A, Nikita E, Hu K, Mulvaney CA, Stead R, et al. Subconjunctival draining minimally-invasive glaucoma devices for medically uncontrolled glaucoma. Cochrane Database of Systematic Reviews 2018, Issue 12. [DOI: 10.1002/14651858.CD012742.pub2]

\section{Kirwan 2013}

Kirwan JF, Lockwood AJ, Shah P, Macleod A, Broadway DC, King AJ, et al. Trabeculectomy in the 21st century: a multicenter analysis. Ophthalmology 2013;120(12):2532-9.

\section{Lavia 2017}

Lavia C, Dallorto L, Maule M, Ceccarelli M, Fea AM. Minimallyinvasive glaucoma surgeries (MIGS) for open angle glaucoma: A systematic review and meta-analysis. PLoS One 2017;8:e0183142.

\section{Le 2019}

Le JT, Bicket AK, Wang L, Li T. Ab interno trabecular bypass surgery with iStent for open-angle glaucoma. Cochrane Database of Systematic Reviews 2019, Issue 3. [DOI: 10.1002/14651858.CD012743.pub2]

\section{Lichter 2001}

Lichter PR, Musch DC, Gillespie BW, Guire KE, Janz NK, Wren PA, et al. Interim clinical outcomes in the Collaborative Initial Glaucoma Treatment Study comparing initial treatment randomized to medications or surgery. Ophthalmology 2001;108(11):1943-53.

\section{Mansberger 2012}

Mansberger SL, Gordon MO, Jampel H, Bhorade A, Brandt JD, Wilson $B$, et al. Reduction in intraocular pressure after cataract extraction: the Ocular Hypertension Treatment Study. Ophthalmology 2012;119(9):1826-31.

\section{Okeke 2009}

Okeke CO, Quigley HA, Jampel HD, Ying GS, Plyler RJ, Jiang Y, et al. Adherence with topical glaucoma medication monitored electronically. The Travatan Dosing Aid study. Ophthalmology 2009;116(2):191-9.

\section{Otarola 2019 [pers comm]}

Otarola F. How many Hydrus devises have been implanted worldwide? [personal communication] Data request for Cochrane Review. Email to: btrauthen@ivantisinc.com 14 September 2019.

\section{Overby 2009}

Overby DR, Stamer WD, Johnson M. The changing paradigm of outflow resistance generation: towards synergistic models of the JCT and inner wall endothelium. Experimental Eye Research 2009;88(4):656-70.

\section{Peters 2013}

Peters D, Bengtsson B, Heijl A. Lifetime risk of blindness in open-angle glaucoma. American Journal of Ophthalmology 2013;156(4):724-30.

\section{Piltz 2000}

Piltz J, Gross R, Shin DH, Beiser JA, Dorr DA, Kass MA, et al. Contralateral effect of topical beta-adrenergic antagonists in initial one-eyed trials in the ocular hypertension treatment study. American Journal of Ophthalmology 2000;130(4):441-53.

\section{Quigley 2006}

Quigley HA, Broman AT. The number of people with glaucoma worldwide in 2010 and 2020. British Journal of Ophthalmology 2006;90(3):262-7.

\section{Radcliffe 2010}

Radcliffe NM, Musch DC, Niziol LM, Liebmann JM, Ritch R, Collaborative Initial Glaucoma Treatment Study Group. The effect of trabeculectomy on intraocular pressure of the untreated fellow eye in the collaborative initial glaucoma treatment study. Ophthalmology 2010;117(11):2055-60. 


\section{Review Manager 2014 [Computer program]}

Nordic Cochrane Centre, The Cochrane Collaboration. Review Manager 5 (RevMan 5). Version 5.3. Copenhagen: Nordic Cochrane Centre, The Cochrane Collaboration, 2014.

\section{Sandhu 2017}

Sandhu A, Jayaram H, Hu K, Bunce C, Gazzard G. Ab interno supraciliary microstent surgery for open angle glaucoma. Cochrane Database of Systematic Reviews 2017, Issue 9. [DOI: 10.1002/14651858.CD012802]

\section{Tóth 2019}

Tóth M, Shah A, Hu K, Bunce C, Gazzard G. Endoscopic cyclophotocoagulation (ECP) for open angle glaucoma and primary angle closure. Cochrane Database of Systematic Reviews 2019, Issue 2. [DOI: 10.1002/14651858.CD012741.pub2]

\section{UKGTS 2015}

Garway-Heath, Crabb DP, Bunce C, Lascaratos G, Amalfitano F, Anand N, Azuara-Blanco A, Bourne RR, Broadway DC, Cunliffe IA, Diamond JP, Fraser SG, Ho TA, Martin KR, McNaught Al, Negi A, Patel K, Russell RA, Shah A, Spry PG, Suzuki K, White ET, Wormald RP, Xing W, Zeyen TG. Latanoprost for open-angle glaucoma (UKGTS): a randomised, multicentre, placebocontrolled trial.. Lancet 2015 Apr 4;385(9975):1295-304.

\section{References to other published versions of this review}

\section{Otarola 2017}

Otarola F, Hu K, Gazzard G, Bunce C. Ab interno trabecular bypass surgery with Schlemm 's Canal Microstent (Hydrus) for open angle glaucoma. Cochrane Database of Systematic Reviews 2017, Issue 8. [DOI: 10.1002/14651858.CD012740]

* Indicates the major publication for the study

\section{CHARACTERISTICS OF STUDIES}

Characteristics of included studies [ordered by study ID]

\section{COMPARE 2019}

Methods Study design: parallel, multicentre, single-masked (participant), randomised controlled trial
Unit of randomisation: participant

Participants

Country: conducted at 12 sites in the United States and 8 international sites

Total number of participants enrolled: 152 participants (152 eyes)

Total number of participants randomised: 152

Number of men and women: women $54.7 \%$ (Hydrus group), $58.4 \%$ (iStent group)

Age range: men: 66.9, SD 10 (Hydrus group), 66.5, SD 9.5 (iStent group)

Inclusion criteria:

- Phakic or pseudophakic

- A diagnosis of POAG treated with hypotensive medications

- Medicated IOP $\leq 31 \mathrm{mmHg}$

- Diurnal IOP $\geq 23 \mathrm{mmHg}$ and $\leq 39 \mathrm{mmHg}$

\section{Exclusion criteria:}

- Congenital or developmental glaucoma

- Previous trabeculectomy or other glaucoma procedure, argon laser trabeculoplasty

- Ab interno or ab externo device implanted in or through Schlemm's canal

- Use of oral hypotensive medication for glaucoma for treatment of fellow eye

Interventions

Intervention: Hydrus microstent $(\mathrm{N}=75)$

Comparator: iStent (n.2) trabecular micro-bypass stent $(\mathrm{N}=77)$

\section{Outcomes}

\section{Primary outcome}

Proportion of participants unmedicated at 12 months following surgery (taken from ClinicalTrials.Gov)

\section{Secondary outcomes}


- Mean change in unmedicated IOP from baseline to 12 months (wash-out was not possible for some participants)

- Mean medication use at 12 and 24 months post procedure

- Surgical success, defined as freedom from secondary surgery, IOP $18 \mathrm{mmHg}$ or less, and discontinuation of all ocular hypotensive medications (taken from report)

- Visual field testing using the 24-2 SITA standard strategy using a Humphrey Visual Field Analyzer (Carl Zeiss Meditech, Jena, Germany) was collected at baseline, 3 and 12 months, but not listed as an outcome measure in ClinicalTrials.Gov and in the published article.

\section{Safety outcomes}

- Intraoperative complications

- Observed rate of ocular adverse events

Length of follow up: 12 months

Funding source: Study sponsored by Ivantis, Inc., Irvine, California

Declaration of interest: several study authors had received honoraria, grants, consulting fees from Ivantis Inc., as well as other companies.

Trial ID: NCT02023242

\section{Risk of bias}

\begin{tabular}{lll}
\hline Bias & Authors' judgement & Support for judgement \\
\hline $\begin{array}{l}\text { Random sequence genera- } \\
\text { tion (selection bias) }\end{array}$ & Low risk & $\begin{array}{l}\text { Quote: "The allocation was determined by a computer generated sequence } \\
\text { stratified by site and prepared in advance by the study statistician in order to } \\
\text { provide balanced study groups" }\end{array}$ \\
\hline $\begin{array}{l}\text { Allocation concealment } \\
\text { (selection bias) }\end{array}$ & Low risk & $\begin{array}{l}\text { Quote: "Randomization was performed in the operating room by opening a se- } \\
\text { quentially numbered envelope" }\end{array}$ \\
\hline $\begin{array}{l}\text { Blinding of participants } \\
\text { and personnel (perfor- } \\
\text { mance bias) }\end{array}$ & Low risk & Comment: not enough details on how the process was managed. \\
$\begin{array}{l}\text { All outcomes } \\
\end{array}$ & & \\
\hline
\end{tabular}

\begin{tabular}{|c|c|c|}
\hline $\begin{array}{l}\text { Blinding of outcome as- } \\
\text { sessment (detection bias) } \\
\text { All outcomes }\end{array}$ & High risk & $\begin{array}{l}\text { Quote: "the investigator at each study site was not masked to treatment ran- } \\
\text { domization during follow-up examinations." }\end{array}$ \\
\hline $\begin{array}{l}\text { Incomplete outcome data } \\
\text { (attrition bias) } \\
\text { All outcomes }\end{array}$ & Low risk & Two participants were lost in each group \\
\hline $\begin{array}{l}\text { Selective reporting (re- } \\
\text { porting bias) }\end{array}$ & Low risk & $\begin{array}{l}\text { There appears to be no major difference between the published report and de- } \\
\text { tails on the protocol in ClinicalTrials.gov; however, visual field was obtained } \\
\text { but not reported. }\end{array}$ \\
\hline
\end{tabular}

Methods Study design: parallel, multicentre, single-masked (participant), randomised controlled trial


Unit of randomisation: participant

Country: conducted at 26 sites in the United States and 12 international sites
Total number of participants enrolled: 1143
Total number of participants randomised: 556 participants (556 eyes)
Number (\%) of men and women: women 55.8 (intervention group), 56.1 (comparator group)
Age range: mean $71.1, \mathrm{SD} 7.9$ (intervention group), $71.2, \mathrm{SD} 7.6$ (comparator group)
Inclusion criteria:
- An operable age-related cataract
- A diagnosis of POAG treated with 1 to 4 hypotensive medications
- Medicated IOP $\leq 31 \mathrm{mmHg}$
- Diurnal IOP $\geq 22 \mathrm{mmHg}$ and $\leq 34$ mmHg
Exclusion criteria:
- Congenital or developmental glaucoma
- Previous argon laser trabeculoplasty
- Ab interno or ab externo device implanted in or through Schlemm's canal
- Use of oral hypotensive medication for glaucoma for treatment of fellow eye

\section{Primary outcome}

- Proportion of eyes at 24 months with unmedicated mean MDIOP reduction $\geq 20 \%$ compared with baseline (taken from study report)

\section{Secondary outcomes}

- Mean change in unmedicated MDIOP from baseline to 24 months

- Changes in mean medication count per participant between baseline and 24 months follow-up.

- Proportion of eye medication free at each visit.

\section{Safety outcomes}

- Intraoperative complications

- Observed rate of ocular adverse events

Length of follow up: 24 months

Adverse events reported: Yes

Sources of funding: Study sponsored by Ivantis, Inc., Irvine, California

Declaration of interest: Several study authors had received honoraria, grants, consulting fees from Ivantis Inc., as well as other companies.

Trial ID: NCT01539239

\section{Risk of bias}

Bias Authors' judgement Support for judgement




\section{HORIZON 2018 (Continued)}

Random sequence genera- Low risk tion (selection bias)

"Upon confirmation, eyes were randomized to either Hydrus Microstent implantation (HMS group) or no microstent implantation (NMS group) using an online computer algorithm in a 2:1 allocation ratio."

$\begin{array}{ll}\begin{array}{l}\text { Allocation concealment } \\ \text { (selection bias) }\end{array} & \text { Low risk } \\ & \begin{array}{l}\text { plantation (HMS group) or no microstent implantation (NMS group) using an } \\ \text { online computer algorithm in a 2:1 allocation ratio." }\end{array}\end{array}$

\begin{tabular}{|c|c|c|}
\hline $\begin{array}{l}\text { Blinding of participants } \\
\text { and personnel (perfor- }\end{array}$ & Low risk & $\begin{array}{l}\text { "Study subjects remained masked to treatment assignment throughout the } \\
\text { course of the study." }\end{array}$ \\
\hline
\end{tabular}

mance bias)

All outcomes

\begin{tabular}{|c|c|c|}
\hline $\begin{array}{l}\text { Blinding of outcome as- } \\
\text { sessment (detection bias) }\end{array}$ & Unclear risk & $\begin{array}{l}\text { "The tonometry protocol utilized a 2-person method: an observer and a reader } \\
\text { who was masked to study treatment." }\end{array}$ \\
\hline All outcomes & & $\begin{array}{l}\text { "Despite multiple measures to minimize bias, it was not possible to mask the } \\
\text { surgeon to treatment group during postoperative examinations." }\end{array}$ \\
\hline
\end{tabular}

$\begin{array}{ll}\begin{array}{l}\text { Incomplete outcome data } \\ \text { (attrition bias) }\end{array} & \text { Unclear risk } \\ \text { All outcomes } & \begin{array}{l}\text { "After accounting for the randomization ratio and } 10 \% \text { annual attrition, the } \\ \text { study size was calculated to be } 558 \text { subjects." }\end{array} \\ & 556 \text { participants were randomized (so trial investigators did try to avoid attri- } \\ & \begin{array}{l}\text { tion bias). } 3 \% \text { were lost to follow-up and } 2 \% \text { died or could not return owing to } \\ \text { non-study-related critical illness. No details given on losses in each study arm } \\ \text { or methods used to account for missing data. }\end{array}\end{array}$

$\begin{array}{ll}\begin{array}{l}\text { Selective reporting (re- } \\ \text { porting bias) }\end{array} & \text { Unclear risk }\end{array} \begin{aligned} & \text { There appears to be no major differences between the published report and } \\ & \text { details on the protocol in ClinicalTrials.gov; however, worsening of visual field } \\ & \text { was not listed as an outcome measure, but was obtained since visual field loss } \\ & \text { by } 2.5 \mathrm{~dB} \text { or more was reported as an adverse event }(4.3 \% \text { for Hydrus and } 5.3 \% \\ & \text { for iStent). }\end{aligned}$

\section{Pfeiffer 2015}

Methods

Study design: Parallel, multicentre, randomised, single-masked (participant), controlled clinical trial

Unit of randomisation: participant

Only 1 eye per participant was eligible for treatment, although both eyes could be screened for inclusion.

"Before surgery, participants were washed out of all hypotensive medications in the study eye for a variable period, depending on the class of medication in use at the time of screening. The washout protocol is described in the Ocular Hypertension Treatment Study. At the completion of the washout, a preoperative baseline diurnal IOP (DIOP) value was obtained by averaging 3 Goldmann tonometry measurements obtained 4 hours apart between 8AM and 4PM. The tonometry protocol used a 2-person system (an observer and a reader), and 2 readings were obtained at each time point during the day. If the difference in the 2 measurements was more than $2 \mathrm{mmHg}$, a third measurement was obtained. The average of 2 measurements or the median value of 3 was used for the time point, and the average of the IOP measurements at all 3 time points was the mean DIOP. The DIOP value was required to be between 21 and $36 \mathrm{mmHg}$ for study inclusion."

Participants

Country: study conducted at 7 European sites: Germany, Spain, the Netherlands, Italy

Total number of participants randomised: $\mathrm{N}=100$

Number of men and women: $40 \%$ men (intervention Group), $58 \%$ (comparator group). 
Pfeiffer 2015 (Continued)

Average age and age range: 21 to 80 years old; mean 72.8, SD 6.6 (intervention group); 71.5, SD 6.9 (comparator group)

Inclusion criteria: People with concurrent cataract and open-angle glaucoma ("IOP of $24 \mathrm{mmHg}$ or less with no more than 4 hypotensive medications, Shaffer grade III or IV chamber angle in all quadrants and Humphrey visual field changes characteristic of glaucoma or glaucomatous optic nerve damage confirmed by ophthalmoscopy and nerve fiber layer imaging").

Exclusion criteria: "Clinical exclusion criteria included angle-closure glaucoma, secondary glaucomas except pseudoexfoliation or pigment dispersion syndromes, exudative age-related macular degeneration (AMD), proliferative diabetic retinopathy, or significant risk of glaucomatous vision loss because of washout of IOP-lowering medications. Anatomic exclusion criteria were narrow angle or other angle abnormality visible on gonioscopy, central corneal thickness of less than $480 \mathrm{~mm}$ or more than $620 \mathrm{~mm}$, or clinically significant corneal dystrophy. participants with prior corneal surgery, argon laser trabeculoplasty, cycloablation, or any incisional glaucoma procedure, such as trabeculectomy, tube shunts, deep sclerectomy, or canaloplasty, also were excluded."

Interventions

Intervention: Hydrus microstent + CS with phacoemulsification (Hydrus + CS) N $=50$

Comparator: CS with phacoemulsification (CS) only $\mathrm{N}=50$

Outcomes

\section{Primary outcome}

- Proportion of participants with a $20 \%$ or more reduction in mean washed-out diurnal IOP at 12 and 24 months.

\section{Secondary outcomes}

- Mean washed-out diurnal IOP

- Proportion of participants taking hypotensive medications

- Proporton of participants using medication throughout the follow-up period

- Number of glaucoma medications at follow-up (24 months)

\section{Safety outcomes}

- Intraoperative complications

- Observed rate of ocular adverse events

- Change in visual acuity

- Secondary glaucoma surgery: 1 (Hydrus + CS), 2 (CS)

Length of follow up: 24 months

Intervals at which outcomes assessed: Follow-up examinations were conducted per protocol at 1 day, 1 week, and 1, 3, 6, 12, 18, and 24 months.

\section{Loss to follow-up}

"Before the 12-month visit, 2 participants from the Hydrus + CS group and 1 participant from the CS group exited the study for non-health-related reasons, for a 12-month subject accountability rate of 97 (97\%) of 100 . Between 12 and 24 months, 4 additional participants exited from the study: 1 participant died of cardiac disease, 1 participant developed lung cancer, 1 declined further participation after secondary glaucoma surgery, and 1 participant was lost to follow-up, all in the CS group, for a 24-month accountability rate of 93 (93\%) of $100 . "$

Adverse events reported: Yes

Notes

Date conducted: Participants randomised to the study from July 2011 to April 2012

Sources of funding: Study sponsored by Ivantis, Inc., Irvine, California

Declaration of interest: The trial investigators have declared their financial disclosures in the trial report including financial support from Ivantis Inc.; Transcend; Glaukos, Innfocus and Alcon.

Trial registration: NCT01818115 
Pfeiffer 2015 (Continued)

Risk of bias

\begin{tabular}{|c|c|c|}
\hline Bias & Authors' judgement & Support for judgement \\
\hline $\begin{array}{l}\text { Random sequence genera- } \\
\text { tion (selection bias) }\end{array}$ & Low risk & $\begin{array}{l}\text { Quote: "... were assigned randomly in a 1:1 ratio according to a comput- } \\
\text { er-generated listing just before surgery" }\end{array}$ \\
\hline $\begin{array}{l}\text { Allocation concealment } \\
\text { (selection bias) }\end{array}$ & Low risk & $\begin{array}{l}\text { Quote: "... were assigned randomly in a 1:1 ratio according to a comput- } \\
\text { er-generated listing just before surgery" }\end{array}$ \\
\hline $\begin{array}{l}\text { Blinding of participants } \\
\text { and personnel (perfor- } \\
\text { mance bias) }\end{array}$ & Low risk & $\begin{array}{l}\text { Quote: "Subjects remained masked to treatment assignment for the course of } \\
\text { the study." }\end{array}$ \\
\hline All outcomes & & Comment: Single-masked study where the personnel were not masked. \\
\hline $\begin{array}{l}\text { Blinding of outcome as- } \\
\text { sessment (detection bias) } \\
\text { All outcomes }\end{array}$ & High risk & $\begin{array}{l}\text { "Masking the surgeon to the assigned treatment was not possible, and be- } \\
\text { cause the microstent is visible on the slit lamp with gonioscopic examination, } \\
\text { masking the treatment group from the IOP assessor during follow-up visits al- } \\
\text { so was not possible." }\end{array}$ \\
\hline $\begin{array}{l}\text { Incomplete outcome data } \\
\text { (attrition bias) } \\
\text { All outcomes }\end{array}$ & Low risk & All participants lost to follow-up were accounted for. \\
\hline $\begin{array}{l}\text { Selective reporting (re- } \\
\text { porting bias) }\end{array}$ & Low risk & $\begin{array}{l}\text { Outcomes match those reported on ClinicalTrials.gov; however, Humphrey vi- } \\
\text { sual field was collected but not listed as an outcome measure and not report- } \\
\text { ed in the manuscript. }\end{array}$ \\
\hline
\end{tabular}

CS: cataract surgery

IOP: intraocular pressure

MDIOP: modified diurnal intraocular pressure

POAG: primary angle glaucoma

Characteristics of studies awaiting assessment [ordered by study ID]

Altafini 2014

\begin{tabular}{ll}
\hline Methods & Randomised controlled trial \\
\hline Participants & People with cataract and open angle glaucoma \\
\hline Interventions & $\begin{array}{l}\text { Micro incision cataract surgery (MICS) phaco with Express P50 implant under scleral flap } \\
\text { MICS safe-phacotrabeculectomy } \\
\text { Phacoemulsification with the new trabecular stent (Hydrus) implant }\end{array}$ \\
\hline Outcomes & Endothelial cell loss \\
\hline Notes & Authors have been contacted but no response as yet
\end{tabular}

Characteristics of ongoing studies [ordered by study ID] 
NCT02024464

Trial name or title

A prospective, multicenter, randomized comparison of the Hydrus microstent to the iStent for lowering intraocular pressure in glaucoma patients undergoing cataract surgery

\begin{tabular}{|c|c|}
\hline Methods & Randomised, parallel assignment, single-masked (participant) \\
\hline Participants & $\begin{array}{l}\text { Listed locations: United States } \\
\text { Total number of participants enrolled: } 300 \\
\text { Age: } 21 \text { years and older } \\
\text { Inclusion Criteria: } \\
\text { - A diagnosis of primary open angle glaucoma (POAG), Pseudoexfoliative (PXG) glaucoma, or pig- } \\
\text { mentary dispersion glaucoma (PDG) } \\
\text { - An operable age-related cataract with BCVA of } 20 / 40 \text { or worse, eligible for phacoemulsification } \\
\text { Exclusion Criteria: } \\
\text { - Forms of primary or secondary glaucoma not listed above } \\
\text { - Prior glaucoma surgery in the study eye }\end{array}$ \\
\hline Interventions & $\begin{array}{l}\text { Intervention: Hydrus microstent } \\
\text { Comparator: iStent trabecular micro-bypass stent }\end{array}$ \\
\hline Outcomes & $\begin{array}{l}\text { Primary outcome (current): IOP at } 24 \text { months following surgery } \\
\text { Primary outcome (original): IOP at } 12 \text { months following surgery } \\
\text { Secondary outcome (current): proportion of eyes with IOP greater than } 5 \text { and less than or equal to } \\
19 \mathrm{mmHg} \text { at } 24 \text { months } \\
\text { Secondary outcome (original): proportion of participants requiring supplemental medication for } \\
\text { pressure control at } 12 \text { months } \\
\text { Other outcomes (current): loss of BCVA at } 24 \text { months } \\
\text { Other outcomes (original): } \\
\text { 1. Proportion of eyes with IOP greater than } 5 \text { and less than or equal to } 19 \mathrm{mmHg} \text { at } 12 \text { months } \\
\text { 2. Loss of BCVA at } 12 \text { months }\end{array}$ \\
\hline Starting date & $\begin{array}{l}\text { August } 2011 \\
\text { Estimated primary completion date: April } 2018 \text { (Final data collection date for primary outcome } \\
\text { measure) }\end{array}$ \\
\hline Contact information & Principal investigator: Iqbal K Ahmed, Canada \\
\hline Notes & Sponsor: Ivantis Inc. \\
\hline
\end{tabular}

BCVA: best-corrected visual acuity IOP: intraocular pressure

\section{DATA AND ANALYSES}


Comparison 1. Cataract surgery + Hydrus microstent vs cataract surgery (CS) alone

\begin{tabular}{|c|c|c|c|c|}
\hline Outcome or subgroup title & $\begin{array}{l}\text { No. of } \\
\text { studies }\end{array}$ & $\begin{array}{l}\text { No. of } \\
\text { partici- } \\
\text { pants }\end{array}$ & Statistical method & Effect size \\
\hline $\begin{array}{l}1 \text { Proportion drop-free: short-term (6 to } 18 \\
\text { months) }\end{array}$ & 2 & 639 & Risk Ratio (M-H, Fixed, 95\% Cl) & $1.59[1.39,1.83]$ \\
\hline $\begin{array}{l}2 \text { Proportion drop-free: medium-term (18 to } \\
36 \text { months) }\end{array}$ & 2 & 619 & Risk Ratio (M-H, Fixed, 95\% Cl) & $1.63[1.40,1.88]$ \\
\hline $\begin{array}{l}3 \text { Mean change in IOP measured using Gold- } \\
\text { mann applanation tonometry: medium-term } \\
\text { (18 to } 36 \text { months) }\end{array}$ & 2 & 619 & Mean Difference (IV, Fixed, 95\% CI) & $-2.0[-2.69,-1.31]$ \\
\hline $\begin{array}{l}4 \text { Mean change in IOP-lowering drops instilled } \\
\text { per day: medium-term ( } 18 \text { to } 36 \text { months) }\end{array}$ & 2 & 619 & Mean Difference (IV, Fixed, 95\% Cl) & $-0.41[-0.56,-0.27]$ \\
\hline $\begin{array}{l}5 \text { Proportion of participants requiring addi- } \\
\text { tional glaucoma surgery or laser }\end{array}$ & 2 & 653 & Risk Ratio (M-H, Fixed, 95\% Cl) & $0.17[0.03,0.86]$ \\
\hline 6 Adverse events: loss of $2+$ VA lines & 2 & 653 & Risk Ratio (M-H, Fixed, 95\% Cl) & $0.46[0.14,1.50]$ \\
\hline 7 Adverse events: IOP spike > 10 mmHg & 2 & 653 & Risk Ratio (M-H, Fixed, 95\% Cl) & $0.39[0.12,1.24]$ \\
\hline 8 Adverse events: bleeding & 2 & & Risk Ratio (M-H, Fixed, 95\% Cl) & $\begin{array}{l}\text { Totals not select- } \\
\text { ed }\end{array}$ \\
\hline
\end{tabular}

Analysis 1.1. Comparison 1 Cataract surgery + Hydrus microstent vs cataract surgery (CS) alone, Outcome 1 Proportion drop-free: short-term (6 to 18 months).

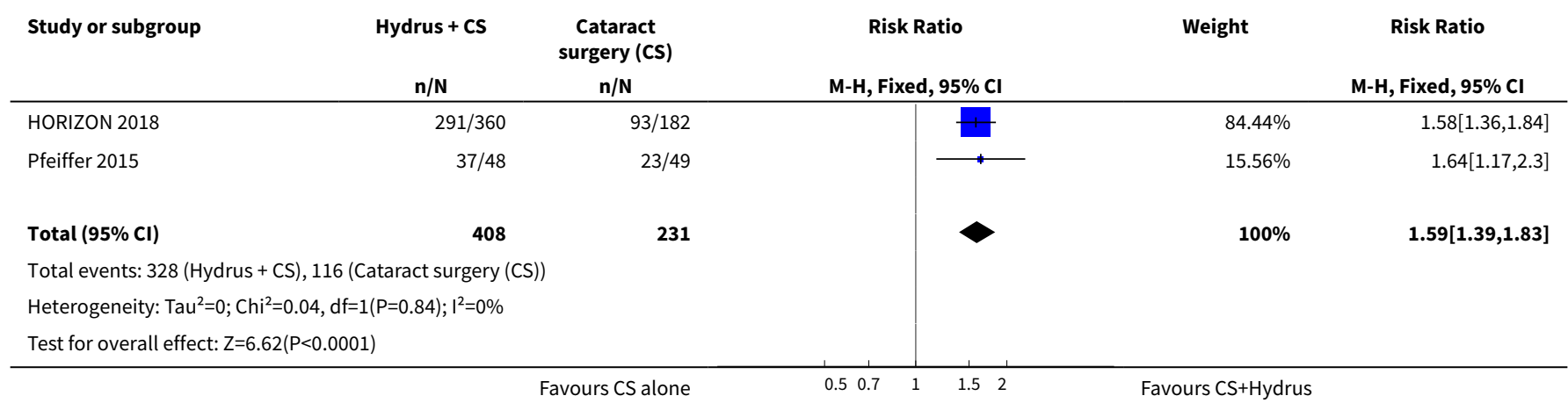

Analysis 1.2. Comparison 1 Cataract surgery + Hydrus microstent vs cataract surgery

(CS) alone, Outcome 2 Proportion drop-free: medium-term (18 to 36 months).

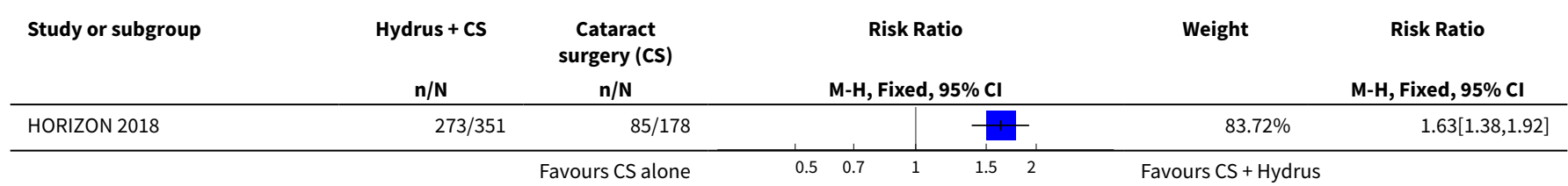




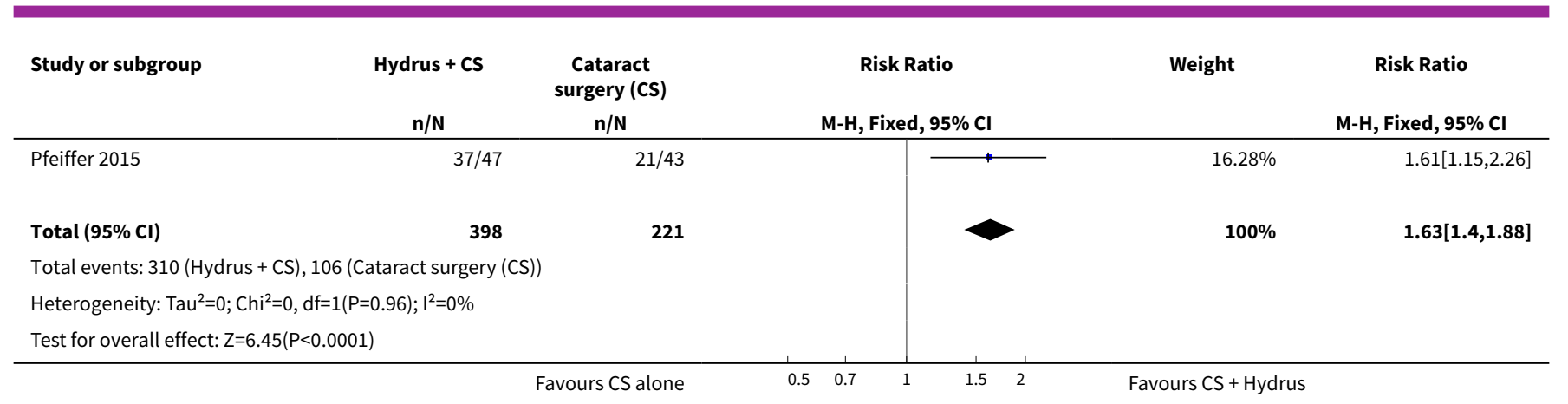

Analysis 1.3. Comparison 1 Cataract surgery + Hydrus microstent vs cataract surgery (CS) alone, Outcome 3 Mean change in IOP measured using Goldmann applanation tonometry: medium-term (18 to 36 months).

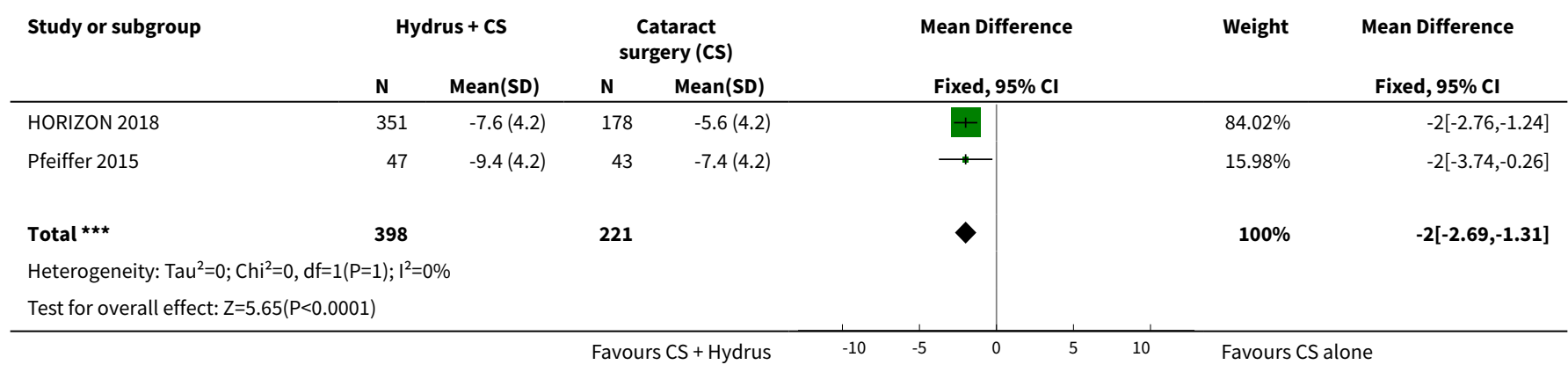

Analysis 1.4. Comparison 1 Cataract surgery + Hydrus microstent vs cataract surgery (CS) alone, Outcome 4 Mean change in IOP-lowering drops instilled per day: medium-term (18 to 36 months).

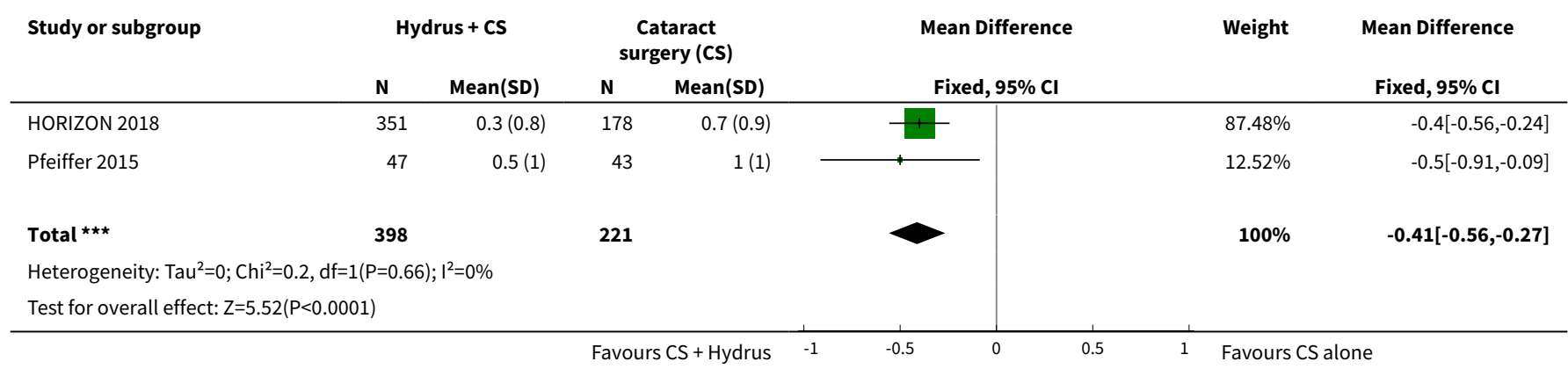

Analysis 1.5. Comparison 1 Cataract surgery + Hydrus microstent vs cataract surgery (CS) alone, Outcome 5 Proportion of participants requiring additional glaucoma surgery or laser.

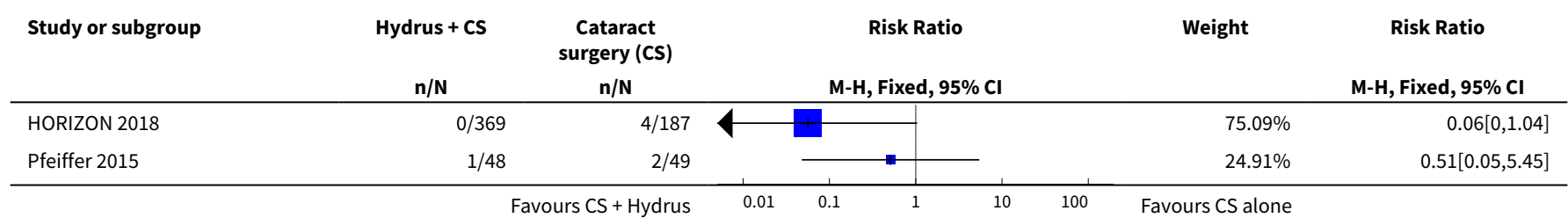




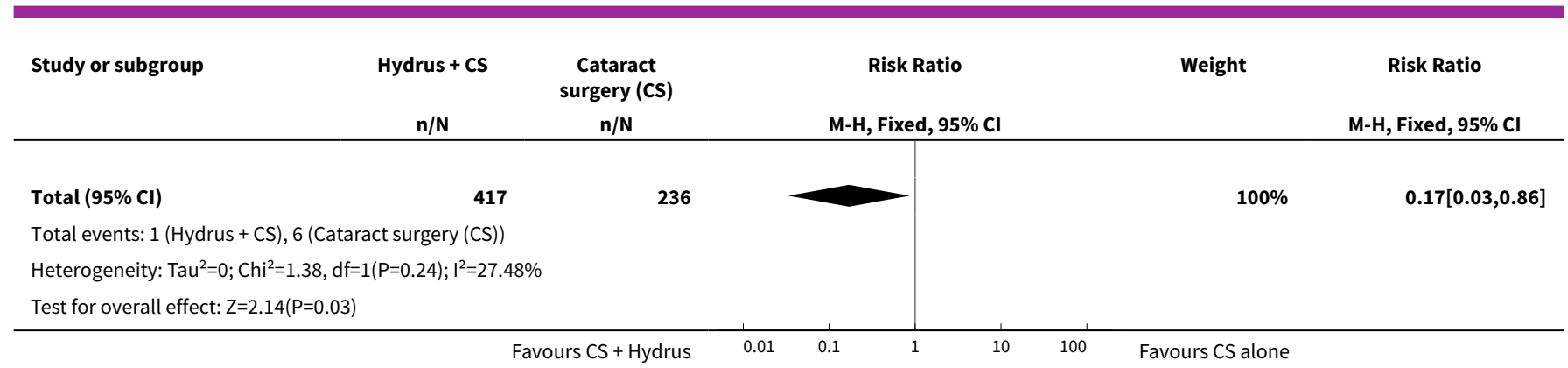

Analysis 1.6. Comparison 1 Cataract surgery + Hydrus microstent vs cataract surgery (CS) alone, Outcome 6 Adverse events: loss of 2+ VA lines.

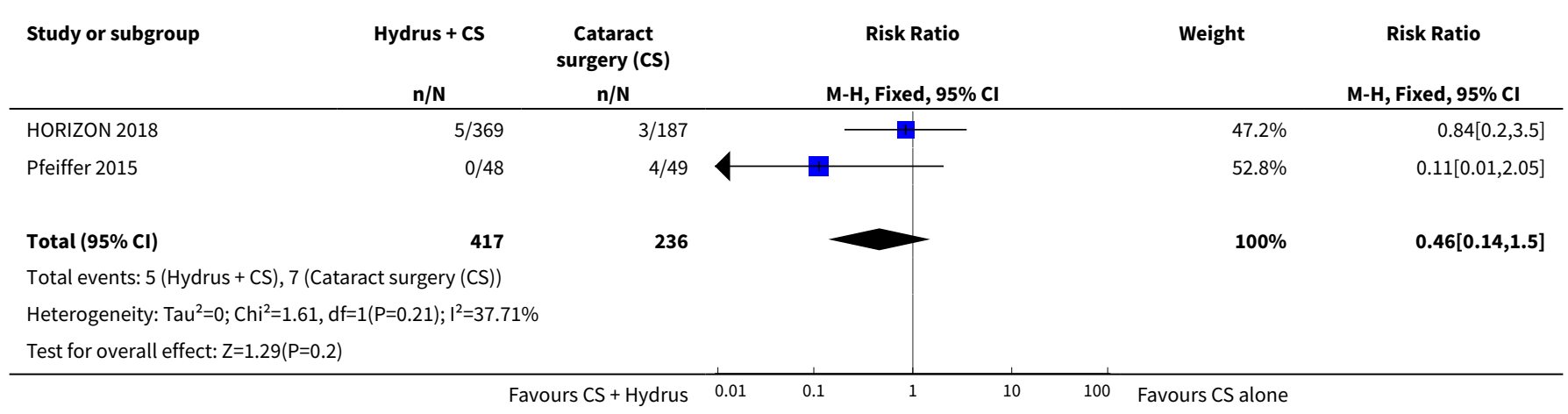

Analysis 1.7. Comparison 1 Cataract surgery + Hydrus microstent vs cataract surgery (CS) alone, Outcome 7 Adverse events: IOP spike $>10 \mathrm{mmHg}$.

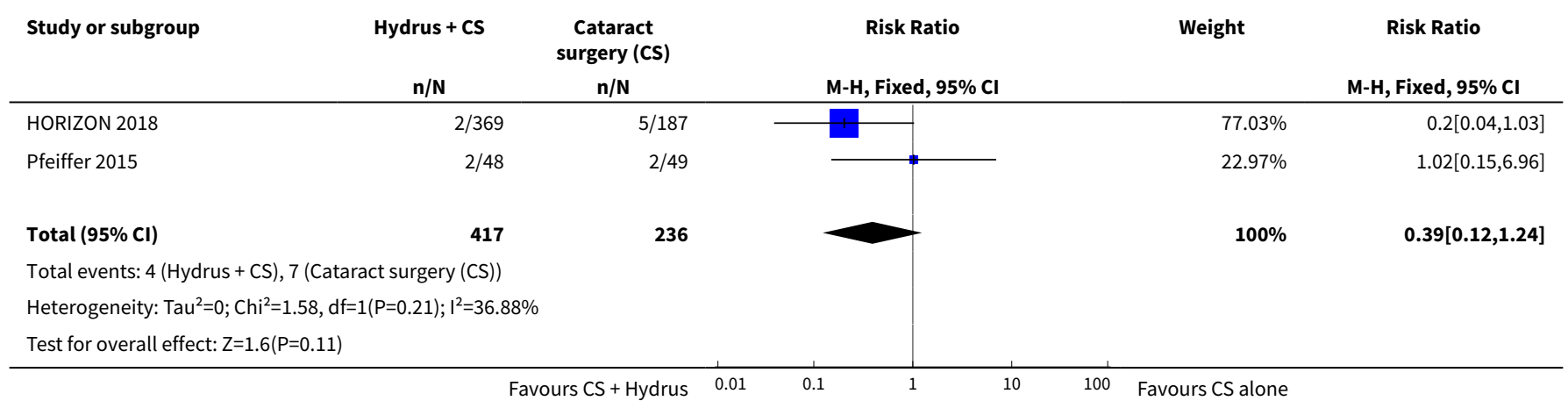

Analysis 1.8. Comparison 1 Cataract surgery + Hydrus microstent vs cataract surgery (CS) alone, Outcome 8 Adverse events: bleeding.

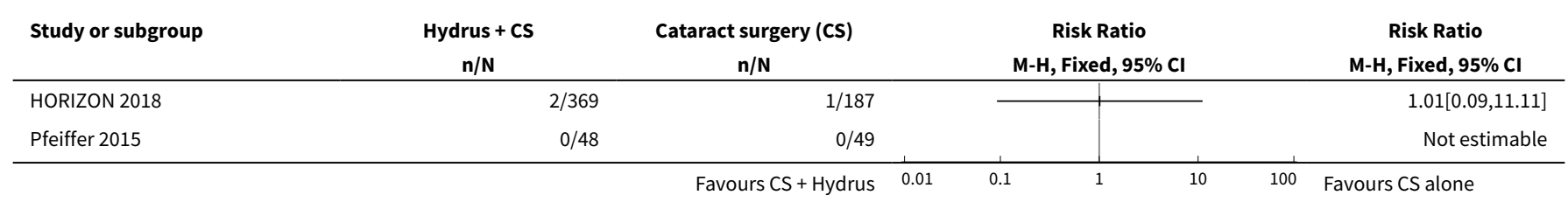


Comparison 2. Hydrus microstent vs iStent trabecular micro-bypass stent

\begin{tabular}{|c|c|c|c|c|}
\hline Outcome or subgroup title & $\begin{array}{l}\text { No. of } \\
\text { studies }\end{array}$ & $\begin{array}{l}\text { No. of } \\
\text { partici- } \\
\text { pants }\end{array}$ & Statistical method & Effect size \\
\hline $\begin{array}{l}1 \text { Proportion drop-free: short-term ( } 6 \text { to } 18 \\
\text { months) }\end{array}$ & 1 & & Risk Ratio (M-H, Fixed, 95\% Cl) & $\begin{array}{l}\text { Totals not select- } \\
\text { ed }\end{array}$ \\
\hline $\begin{array}{l}2 \text { Mean change in IOP measured using Gold- } \\
\text { mann applanation tonometry: short-term ( } 6 \text { to } 18 \\
\text { months) }\end{array}$ & 1 & & $\begin{array}{l}\text { Mean Difference (IV, Fixed, 95\% } \\
\mathrm{CI})\end{array}$ & $\begin{array}{l}\text { Totals not select- } \\
\text { ed }\end{array}$ \\
\hline $\begin{array}{l}3 \text { Mean change in IOP-lowering drops instilled per } \\
\text { day: short-term ( } 6 \text { to } 18 \text { months) }\end{array}$ & 1 & & $\begin{array}{l}\text { Mean Difference (IV, Fixed, 95\% } \\
\mathrm{CI} \text { ) }\end{array}$ & $\begin{array}{l}\text { Totals not select- } \\
\text { ed }\end{array}$ \\
\hline 4 Proportion of participants with IOP $<21 \mathrm{mmHg}$ & 1 & & Risk Ratio (M-H, Fixed, 95\% Cl) & $\begin{array}{l}\text { Totals not select- } \\
\text { ed }\end{array}$ \\
\hline
\end{tabular}

Analysis 2.1. Comparison 2 Hydrus microstent vs iStent trabecular microbypass stent, Outcome 1 Proportion drop-free: short-term (6 to 18 months).

\begin{tabular}{|c|c|c|c|c|c|}
\hline Study or subgroup & $\begin{array}{c}\text { Hydrus } \\
\mathrm{n} / \mathrm{N}\end{array}$ & $\begin{array}{l}\text { iStent } \\
\mathrm{n} / \mathrm{N}\end{array}$ & $\begin{array}{r}\mathbf{R i} \\
M-H, F \\
\end{array}$ & $\begin{array}{l}\text { k Ratio } \\
\text { red, } 95 \% \text { CI }\end{array}$ & $\begin{array}{c}\text { Risk Ratio } \\
\text { M-H, Fixed, } 95 \% \mathrm{Cl}\end{array}$ \\
\hline COMPARE 2019 & $34 / 73$ & $18 / 75$ & & 1 & $1.94[1.21,3.11]$ \\
\hline
\end{tabular}

Analysis 2.2. Comparison 2 Hydrus microstent vs iStent trabecular micro-bypass stent, Outcome 2 Mean change in IOP measured using Goldmann applanation tonometry: short-term (6 to 18 months).

\begin{tabular}{|c|c|c|c|c|c|c|c|}
\hline \multirow{3}{*}{$\begin{array}{l}\text { Study or subgroup } \\
\text { COMPARE } 2019\end{array}$} & \multicolumn{2}{|c|}{ Hydrus } & \multicolumn{2}{|c|}{ iStent } & \multirow{2}{*}{\multicolumn{2}{|c|}{$\begin{array}{c}\text { Mean Difference } \\
\text { Fixed, } 95 \% \mathrm{Cl}\end{array}$}} & \multirow{3}{*}{$\begin{array}{c}\text { Mean Difference } \\
\text { Fixed, } 95 \% \text { Cl } \\
-3.1[-4.17,-2.03]\end{array}$} \\
\hline & \multirow{2}{*}{$\frac{\mathbf{N}}{73}$} & \multirow{2}{*}{$\frac{\text { Mean(SD) }}{-8.2(3.7)}$} & \multirow{2}{*}{$\frac{\mathbf{N}}{75}$} & \multirow{2}{*}{$\frac{\text { Mean(SD) }}{-5.1(2.9)}$} & & & \\
\hline & & & & & + & & \\
\hline
\end{tabular}

Analysis 2.3. Comparison 2 Hydrus microstent vs iStent trabecular micro-bypass stent, Outcome 3 Mean change in IOP-lowering drops instilled per day: short-term (6 to 18 months).

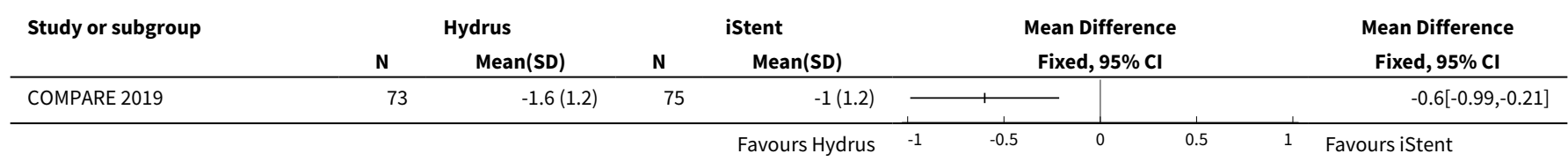


Analysis 2.4. Comparison 2 Hydrus microstent vs iStent trabecular microbypass stent, Outcome 4 Proportion of participants with IOP $<21 \mathrm{mmHg}$.

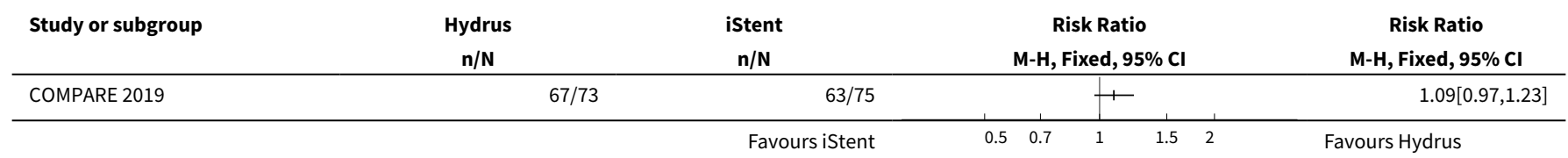

\section{APPENDICES}

\section{Appendix 1. CENTRAL search strategy}

\#1 MeSH descriptor: [Glaucoma, Open-Angle] explode all trees \#2 MeSH descriptor: [Intraocular Pressure] explode all trees \#3 MeSH descriptor: [Ocular Hypertension] explode all trees \#4 OAG or POAG or IOP or OHT \#5 simple near/3 glaucoma* \#6 open near/2 angle near/2 glaucoma* \#7 chronic near/2 glaucoma* \#8 secondary near/2 glaucoma* \#9 low near/2 tension near/2 glaucoma* \#10 low near/2 pressure near/2 glaucoma* \#11 normal near/2 tension near/2 glaucoma* \#12 normal near/2 pressure near/2 glaucoma* \#13 pigment near/2 glaucoma* \#14 MeSH descriptor: [Exfoliation Syndrome] this term only \#15 exfoliat* near/2 syndrome* \#16 exfoliat* near/2 glaucoma* \#17 pseudoexfoliat* near/2 syndrome* $\# 18$ p seudoexfoliat* near/2 glaucoma* $\# 19 \# 1$ or \#2 or \#3 or \#4 or \#5 or \#6 or \#7 or \#8 or \#9 or \#10 or \#11 or \#12 or \#13 or \#14 or \#15 or \#16 or \#17 or \#18 \#20 Schlemm near/4 (microstent ${ }^{\star}$ or scaffold ${ }^{\star}$ )

\#21Hydrus

\#22 \#20 or \#21

$\# 23$ \#19 and \#22

\section{Appendix 2. MEDLINE Ovid search strategy}

1. randomized controlled trial.pt.

2. (randomized or randomised).ab,ti.

3. placebo.ab,ti.

4. dt.fs.

5. randomly.ab,ti.

6. trial.ab,ti.

7. groups.ab,ti.

8. or/1-7

9. exp animals/

10. exp humans/

11. 9 not (9 and 10)

12. 8 not 11

13. exp glaucoma open angle/

14. exp intraocular pressure/

15. ocular hypertension/

16. (OAG or POAG or IOP or OHT).tw.

17. (simple\$ adj3 glaucoma\$).tw.

18. (open adj2 angle adj2 glaucoma\$).tw.

19. (primary adj2 glaucoma\$).tw.

20. (chronic adj2 glaucoma\$).tw. 
21. (secondary adj2 glaucoma\$).tw.

22. (low adj2 tension adj2 glaucoma\$).tw.

23. (low adj2 pressure adj2 glaucoma\$).tw.

24. (normal adj2 tension adj2 glaucoma\$).tw.

25. (normal adj2 pressure adj2 glaucoma\$).tw.

26. (pigment\$ adj2 glaucoma\$).tw.

27. exfoliation syndrome/

28. (exfoliat\$ adj2 syndrome\$).tw.

29. (exfoliat\$ adj2 glaucoma\$).tw.

30. (pseudoexfoliat\$ adj2 syndrome\$).tw.

31. (pseudoexfoliat\$ adj2 glaucoma\$).tw.

32. or/13-31

33. (Schlemm\$ adj4 (microstent\$ or scaffold\$)).tw.

34. Hydrus.tw.

35. or/33-34

36.32 and 35

37.12 and 36

The search filter for trials at the beginning of the MEDLINE strategy is from the published paper by Glanville 2006.

\section{Appendix 3. Embase Ovid search strategy}

1. exp randomized controlled trial/

2. exp randomization/

3. exp double blind procedure/

4. exp single blind procedure/

5. random\$.tw.

6. or/1-5

7. (animal or animal experiment).sh.

8. human.sh.

9.7 and 8

10.7 not 9

11.6 not 10

12. exp clinical trial/

13. (clin\$ adj3 trial\$).tw.

14. ((singl\$ or doubl\$ or trebl\$ or tripl\$) adj3 (blind\$ or mask\$)).tw.

15. exp placebo/

16. placebo\$.tw.

17. random $\$$.tw.

18. exp experimental design/

19. exp crossover procedure/

20. exp control group/

21. exp latin square design/

22. or/12-21

23. 22 not 10

24. 23 not 11

25. exp comparative study/

26. exp evaluation/

27. exp prospective study/

28. (control\$ or prospectiv\$ or volunteer\$).tw.

29. or $/ 25-28$

30. 29 not 10

31.30 not ( 11 or 23 )

32. 11 or 24 or 31

33. open angle glaucoma/

34. intraocular pressure/

35. intraocular hypertension/

36. (OAG or POAG or IOP or OHT).tw.

37. (open adj2 angle adj2 glaucoma\$).tw.

38. (primary adj2 glaucoma\$).tw.

39. (chronic adj2 glaucoma\$).tw.

40. (secondary adj2 glaucoma\$).tw. 
41. (low adj2 tension adj2 glaucoma\$).tw.

42. (low adj2 pressure adj2 glaucoma\$).tw.

43. (normal adj2 tension adj2 glaucoma\$).tw.

44. (normal adj2 pressure adj2 glaucoma\$).tw.

45. (pigment\$ adj2 glaucoma\$).tw.

46. exfoliation syndrome/

47. (exfoliat\$ adj2 syndrome\$).tw.

48. (exfoliat\$ adj2 glaucoma\$).tw.

49. (pseudoexfoliat\$ adj2 syndrome\$).tw.

50. (pseudoexfoliat\$ adj2 glaucoma\$).tw.

51. or/33-50

52. (Schlemm\$ adj4 (microstent\$ or scaffold\$)).tw.

53. Hydrus.tw.

54.52 or 53

55.51 and 54

56.32 and 55

\section{Appendix 4. ISRCTN search strategy}

(Schlemms canal microstent OR Schlemms canal scaffold OR HYDRUS)

\section{Appendix 5. ClinicalTrials.gov search strategy}

(Schlemms canal microstent OR Schlemms canal scaffold OR HYDRUS)

\section{Appendix 6. WHO ICTRP search strategy}

Schlemms canal microstent OR Schlemms canal scaffold OR HYDRUS

Appendix 7. Data on study characteristics

\begin{tabular}{|c|c|c|}
\hline \multicolumn{2}{|l|}{ Mandatory items } & \multirow[t]{2}{*}{ Optional items } \\
\hline Methods & & \\
\hline \multirow[t]{5}{*}{ Study design } & - Parallel group $\mathbf{R C T}$ i.e. people randomised to treatment & Number of study arms \\
\hline & - Within-person RCT i.e. eyes randomised to treatment & Method of randomisation \\
\hline & - Cluster RCT i.e. communities randomised to treatment & Exclusions after randomisation \\
\hline & Cross-over RCT & Losses to follow-up \\
\hline & - Other, specify & Number randomised/analysed \\
\hline Eyes & - One eye included in study, specify how eye selected & Method of masking \\
\hline \multirow[t]{3}{*}{$\begin{array}{l}\text { Unit of randomi- } \\
\text { sation/ unit of } \\
\text { analysis }\end{array}$} & $\begin{array}{l}\text { - Two eyes included in study, both eyes received same treatment, } \\
\text { briefly specify how analysed (best/worst/average/both and adjusted for } \\
\text { within person correlation/both and not adjusted for within person correla- }\end{array}$ & $\begin{array}{l}\text { How were missing data handled? } \\
\text { e.g. available case analysis, impu- } \\
\text { tation methods }\end{array}$ \\
\hline & & Reported power calculation $(\mathrm{Y} / \mathrm{N})$, \\
\hline & $\begin{array}{l}\text { Two eyes included in study, eyes received different treatments, speci- } \\
\text { fy if correct pair-matched analysis done }\end{array}$ & $\begin{array}{l}\text { if yes, sample size and power } \\
\text { Unusual study design/issues }\end{array}$ \\
\hline \multicolumn{3}{|l|}{ Participants } \\
\hline \multirow[t]{3}{*}{ Country } & - & Setting \\
\hline & & Ethnic group \\
\hline & & Method of recruitment \\
\hline
\end{tabular}


(Continued)

Total number of participants

Number (\%) of

men and women
This information should be collected for total study population recruited into the study. If these data are reported for the people who were followed up only, please indicate.

\section{Participation rate}

Equivalence of baseline characteristics $(\mathrm{Y} / \mathrm{N})$

Diagnostic criteria

\section{Average age and} age range

\section{Inclusion criteria}

Exclusion criteria

\section{Interventions}

\begin{tabular}{lll}
\hline Intervention $(\mathrm{N}=)$ & $\cdot$ Number of people randomised to this group & $\begin{array}{l}\text { Comparator parameters, e.g. } \\
\text { dosage of drugs }\end{array}$ \\
Comparator $(\mathrm{N}=)$ & $\cdot$ Intervention name & $\cdot$ Comparator name \\
& $\begin{array}{l}\text { Specify whether phacoemulsification, or other intervention, performed at } \\
\text { same time as intervention }\end{array}$
\end{tabular}

\section{Outcomes}

Primary and secondary outcomes as defined in study reports

\section{- IOP at baseline}

- IOP at follow-up

- Number of glaucoma medications at baseline

- Number of glaucoma medications at follow-up

- Intraoperative complications

- Postoperative complications or secondary surgery

- Duration of follow-up

- Loss to follow-up

- Intervals at which outcomes assessed

Adverse events reported $(\mathrm{Y} / \mathrm{N})$
Planned/actual length of follow-up

\section{Notes}

\begin{tabular}{lll}
\hline Date conducted & Specify dates of recruitment of participants $\mathrm{mm} / \mathrm{yr}$ to $\mathrm{mm} / \mathrm{yr}$ & Full study name: (if applicable) \\
\hline Sources of funding & - & Date of publication \\
\hline $\begin{array}{l}\text { Declaration of in- } \\
\text { terest }\end{array}$ & Reported subgroup analyses (Y/ \\
& $\mathrm{N})$ & Were trial investigators contact- \\
& ed?
\end{tabular}




\section{CONTRIBUTIONS OF AUTHORS}

Francisco Otarola, Kuang Hu and Catey Bunce wrote the protocol. All authors reviewed and approved the protocol.

Francisco Otarola, Gianni Virgili, Anupa Shah, and Kuang Hu screened the search results, extracted the data from the included studies, and wrote the review. All authors reviewed and approved the review.

\section{DECLARATIONS OF INTEREST}

FO has no conflict of interest to declare.

GV has no conflict of interest to declare.

AS has no conflict of interest to declare.

KH performs minimally-invasive glaucoma surgery. He has lectured on 'Constructing clinical trials for MIGS - the lack of evidence and what to do about it' at the Moorfields International Glaucoma Symposium 2016, sponsored by Laboratoires Thea, which is contributing an educational grant to Moorfields Eye Hospital.

CB has no conflict of interest to declare.

GG: In the last five years, GG has received travel funding, and his host organisation has received both educational and unrestricted research funding from pharmaceutical and equipment manufacturers that are involved in the treatment of glaucoma, but none that are otherwise related to (or competing with) the subject of this review.

\section{SOURCES OF SUPPORT}

\section{Internal sources}

- National Institute for Health Research (NIHR), UK.

CB acknowledges financial support for her CEV research sessions from the Department of Health through the award made by the NIHR to Moorfields Eye Hospital NHS Foundation Trust and UCL Institute of Ophthalmology for a Specialist Biomedical Research Centre for Ophthalmology

GG acknowledges support for this research by the NIHR Biomedical Research Centre based at Moorfields Eye Hospital NHS Foundation Trust and UCL Institute of Ophthalmology.

The views expressed in this publication are those of the authors and not necessarily those of the NIHR, NHS, or the Department of Health.

\section{External sources}

- National Institute for Health Research (NIHR), UK.

* Richard Wormald, Co-ordinating Editor for Cochrane Eyes and Vision (CEV) acknowledges financial support for his CEV research sessions from the Department of Health through the award made by the National Institute for Health Research to Moorfields Eye Hospital NHS Foundation Trust and UCL Institute of Ophthalmology for a Specialist Biomedical Research Centre for Ophthalmology

* This review was supported by the NIHR, via Cochrane Infrastructure funding to the CEV UK editorial base

The views and opinions expressed therein are those of the authors and do not necessarily reflect those of the Systematic Reviews Programme, NIHR, NHS, or the Department of Health.

\section{DIFFERENCES BETWEEN PROTOCOLANDREVIEW}

- The follow-up times for the outcomes were decided after the protocol was published.

- Two additional co-authors, A Shah and G Virgili joined the review team.

- The protocol included combination therapy with phacoemulsification as a separate comparison, and also for subgroup analysis. After discussion within the review team and MIGS Consortium, we opted to include it as a separate comparison, as this is likely to be a different indication.

- We changed the objectives and removed the restriction to the inclusion of participants with medically uncontrolled glaucoma; explanations are given in the text as appropriate.

- We added the secondary outcome: rate of visual field progression (DB/time) or proportion of participants whose field loss progressed in the follow-up period.

- In the 'Summary of findings' table, intraoperative and postoperative complications were pooled as a single outcome. 